\title{
Characteristic Patterns of Dendritic Remodeling in Early-Stage Glaucoma: Evidence from Genetically Identified Retinal Ganglion Cell Types
}

\author{
Rana N. El-Danaf ${ }^{1,2,3}$ and Andrew D. Huberman ${ }^{1,2,3,4}$ \\ ${ }^{1}$ Department of Neurosciences, ${ }^{2}$ Neurobiology Section in the Division of Biological Sciences, and ${ }^{3}$ Department of Ophthalmology, University of California, \\ San Diego, La Jolla, California 92093, and ${ }^{4}$ Salk Institute for Biological Studies, La Jolla, California 92093
}

Retinal ganglion cell (RGC) loss is a hallmark of glaucoma and the second leading cause of blindness worldwide. The type and timing of cellular changes leading to RGC loss in glaucoma remain incompletely understood, including whether specific RGC subtypes are preferentially impacted at early stages of this disease. Here we applied the microbead occlusion model of glaucoma to different transgenic mouse lines, each expressing green fluorescent protein in 1-2 specific RGC subtypes. Targeted filling, reconstruction, and subsequent comparison of the genetically identified RGCs in control and bead-injected eyes revealed that some subtypes undergo significant dendritic rearrangements as early as $7 \mathrm{~d}$ following induction of elevated intraocular pressure (IOP). By comparing specific On-type, On-Offtype and Off-type RGCs, we found that RGCs that target the majority of their dendritic arbors to the scleral half or "Off" sublamina of the inner plexiform layer (IPL) undergo the greatest changes, whereas RGCs with the majority of their dendrites in the On sublamina did not alter their structure at this time point. Moreover, M1 intrinsically photosensitive RGCs, which functionally are On RGCs but structurally stratify their dendrites in the Off sublamina of the IPL, also underwent significant changes in dendritic structure 1 week after elevated IOP. Thus, our findings reveal that certain RGC subtypes manifest significant changes in dendritic structure after very brief exposure to elevated IOP. The observation that RGCs stratifying most of their dendrites in the Off sublamina are first to alter their structure may inform the development of new strategies to detect, monitor, and treat glaucoma in humans.

Key words: dendrites; glaucoma; retinal ganglion cells

\section{Introduction}

Glaucoma is a common CNS neurodegenerative disease and the second leading cause of blindness (Quigley and Broman, 2006; Pascolini and Mariotti, 2012). The hallmark feature of glaucoma is damage and loss of retinal ganglion cells (RGCs), the neurons that connect the eyes to the brain (Quigley, 1999; Weinreb and Khaw, 2004; Casson et al., 2012). Glaucoma is often associated with elevated intraocular pressure (IOP; Sommer, 1989; Peters et al., 2014) and pressure-lowering agents can be effective in slowing RGC loss (Morrison et al., 1998; Heijl et al., 2002; Kass et al., 2002; Lichter, 2002; Kim et al., 2013). Even with pressurelowering drugs, however, RGCs eventually die. Understanding the timing and pattern of cellular changes leading to RGC death

Received April 4, 2014; revised Nov. 13, 2014; accepted Dec. 15, 2014.

Author contributions: R.N.E.-D. and A.D.H. designed research; R.N.E.-D. and A.D.H. performed research; R.N.E.-D. analyzed data; R.N.E.-D. and A.D.H. wrote the paper.

This work was supported by a grant from The Glaucoma Research Foundation Catalyst for a Cure (A.D.H. and R.N.E.-D.) and the E. Matilda Ziegler Foundation for the Blind (A.D.H.). We thank Drs. David Berson, Rachel Wong, Jeff Goldberg, Alf Dubra, and Vivek Srinivasan, as well as members of the Huberman laboratory for their helpful comments and suggestion on an earlier version of this manuscript. We also thank J. Bradley Segal for collecting preliminary data for this project, and Ann Phan for assistance with cell counts.

The authors declare no competing financial interests.

Correspondence should be addressed to Andrew D. Huberman at the above address. E-mail: ahuberman@ucsd.edu.

DOI:10.1523/JNEUROSCI.1419-14.2015

Copyright $\odot 2015$ the authors $\quad 0270-6474 / 15 / 352329-15 \$ 15.00 / 0$ in glaucoma should facilitate the development of tools to detect and impede those cellular changes and ultimately to preserve vision.

Several experimental models (Bouhenni et al., 2012; VidalSanz et al., 2012) indicate that RGC death is a relatively late event in glaucoma, and is preceded by axonal transport defects, which can occur even within days of IOP elevation and before axonal loss (Buckingham et al., 2008; Crish et al., 2010; Chen et al., 2011; Calkins, 2012; Ward et al., 2014). Also, Wong and coworkers recently reported that dendritic and/or electrophysiological changes occur in subsets of RGCs as early as 2 weeks after IOP elevation (Della Santina et al., 2013). Whether changes in RGC dendritic structure occur during the period immediately following the induction of elevated IOP, however, remains unresolved.

A persistent barrier to understanding the pathogenesis of glaucoma is the wide diversity of RGC subtypes (Berson, 2008; Dhande and Huberman, 2014). In recent years, we discovered and characterized various transgenic mouse lines, each with 1-2 distinct RGC subtypes selectively expressing green fluorescent protein (GFP; Huberman et al., 2008, 2009; Osterhout et al., 2011; Rivlin-Etzion et al., 2011; Dhande et al., 2013). These mice raise the opportunity to study the detailed morphological and functional changes occurring in defined RGC populations in response to various experimental perturbations. Here we applied the "microbead occlusion" model of glaucoma (Sappington et al., 
Table 1. Summary of transgenic mice and antibody labeling used for labeling RGC subtypes

\begin{tabular}{lll}
\hline Mouse line/stain & Labeled RGC subtype & Reference \\
\hline CB2-GFP & tOff- $\alpha$ & Huberman et al., 2008 \\
Hoxd10-GFP & On DSGC & Dhande et al., 2013 \\
Anti-melanopsin & aOn-Off DSGC & \\
\hline
\end{tabular}

2010; Chen et al., 2011) to two of these transgenic mouse lines, which collectively label three RGC subtypes: (1) an Off- $\alpha$ RGC subtype (Huberman et al., 2008), (2) an On-direction selective RGC subtype, and (3) an On-Off-direction selective RGC subtype (Dhande et al., 2013). We also used the antibody against melanopsin protein to label and examine type 1 intrinsically photosensitive RGCs (M1 ipRGCs; Berson et al., 2010; Table 1). We tested whether there are dendritic morphological changes that occur in any of the labeled RGC populations 1 week following induction of elevated IOP, an early stage that, to our knowledge, has not been examined. Our goal was also to determine whether the dendrites and somas of some RGC subtypes are impacted more than others at this stage and to determine whether any such changes predicted rates of RGC death at later time points. The idea that some RGC subtypes are more vulnerable to aging and/or glaucoma has existed for some time, but has been met with contradictory evidence (Quigley et al., 1988; Glovinsky et al., 1991; Weber et al., 1998; Morgan et al., 2000; Pavlidis et al., 2003; Shou et al., 2003; Jakobs et al., 2005; Li et al., 2006; Samuel et al., 2011; Della Santina et al., 2013; Feng et al., 2013). Our results indicate that dendritic rearrangements of RGCs that stratify primarily in the Off sublamina of the inner retina are among the earliest structural changes in glaucoma. Moreover, the RGCs that undergo these early stages are among the first to die. These findings point to the specific structural features and cell types in the retina that may act as key factors involved in the progression of glaucoma.

\section{Materials and Methods}

Animals. All experimental procedures were approved by the Institutional Animal Care and Use Committee at the University California, San Diego. All mice used in this study were 1 month old or older [postnatal day (P) 31-P73]. Both male and female mice were used in this study in equal numbers. The following bacterial artificial chromosome (BAC) transgenic mouse lines were used: Calretinin-EGFP (CB2-GFP; Huberman el al., 2008) and Homeobox d10-EGFP (Hoxd10-GFP; Dhande et al., 2013; Table 1). Founder mice were backcrossed onto C57BL/6 for $\geq 4$ generations and their offspring used in this study.

Bead injections. Elevation of IOP was induced using the microbead occlusion model described previously (Sappington et al., 2010; Chen et al., 2011; Fig. 1). Mice from one group were anesthetized with an isoflurane-oxygen mixture $(2-4 \% \mathrm{v} / \mathrm{v})$ at a flow rate of $1.21 \mathrm{~L} / \mathrm{min}$, and a small hole was made in the cornea using a 30 gauge needle. A $2-3 \mu$ lvolume of polyesterene beads ( $10 \mu \mathrm{m}$; Invitrogen F-8834) was injected into the anterior chamber using a Hamilton syringe with 33 gauge needle. The needle also contained a small volume $(0.1-0.5 \mu \mathrm{l})$ of sodium hyaluronate (Alcon Laboratories) to keep the beads from exiting the eye after the injection (Cone et al., 2010; Frankfort et al., 2013). For every animal, one eye received the bead injection and the other eye served as an internal control in which a hole was made in the cornea but no beads were injected. A second group of mice were anesthetized with a mixture of ketamine/ xylazine and a hole was made in the cornea using a glass micropipette attached to a picospritzer. One microliter of the $10 \mu \mathrm{m}$ microbeads was delivered into one eye, while the other eye received a $1 \mu \mathrm{l}$ injection of saline. For both groups, IOPs were measured using a rebound tonometer (TonoLab, Colonial Medical Supply). Six to 10 consecutive IOP measurements were made daily, and the IOP reported for that day was the average of all the readings. Pressures were monitored at the same time
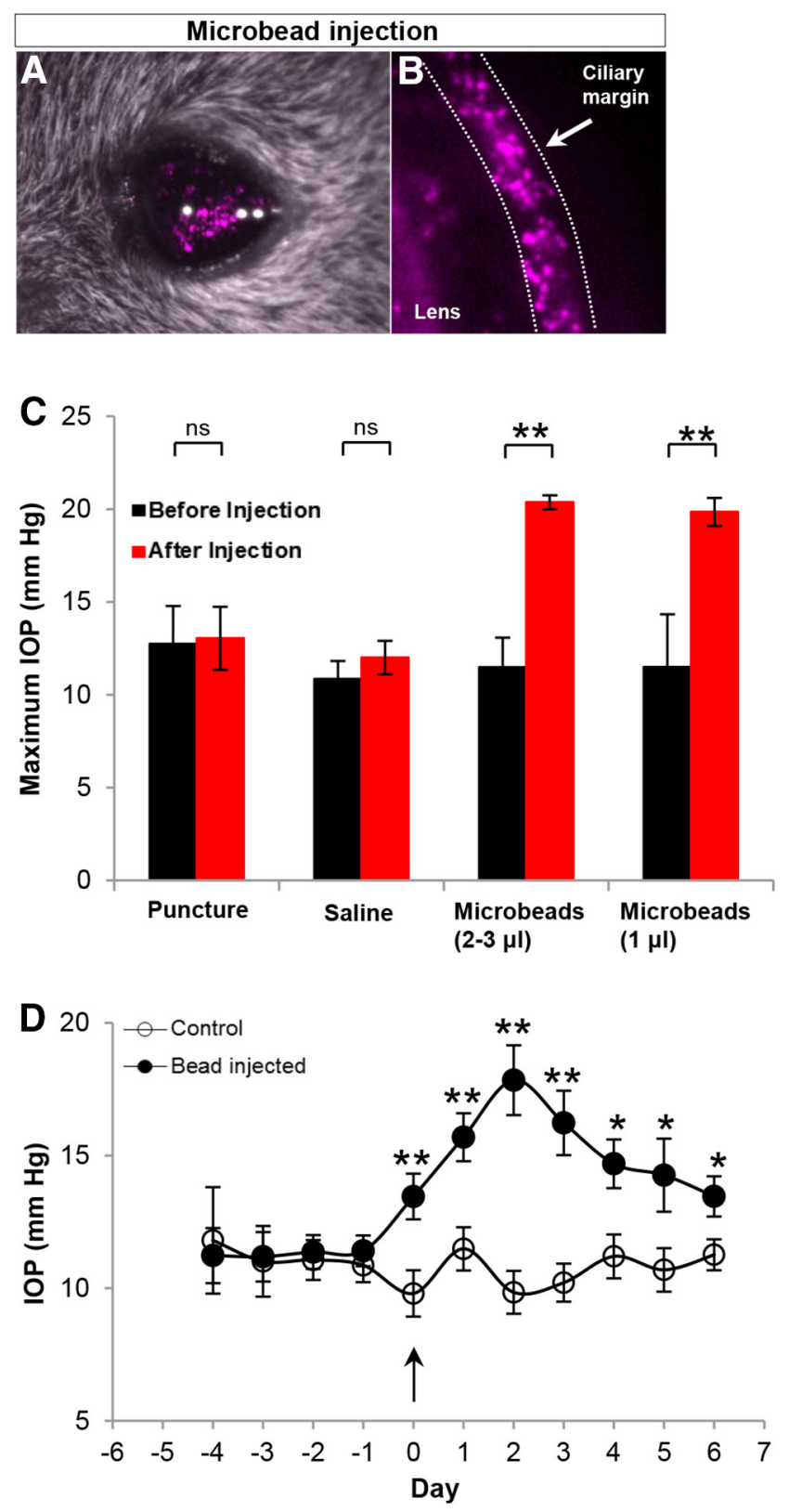

Figure 1. Elevation of IOP with bead occlusion. $\boldsymbol{A}, \boldsymbol{B}$, Microbeads (10 $\mu \mathrm{m})$ injected in the anterior chamber of one eye and confirmed by in vivo fluorescent microscopy. Beads prevent the aqueous outflow through the trabecular meshwork, thus inducing elevation of IOP. C, Quantification of maximum IOP (at any point before or within the week after bead injection) in control and bead-injected eyes, before (baseline; black) and after bead injection (red). Bead injection causes a significant increase in IOP relative to baseline and to controls. $D$, Plot showing the daily average IOPs in the eyes of the control group (empty circles) and the eyes of the bead-injected group (filled circles). Arrow, IOP after bead injection. $N=17$ mice. Error bars: $\pm S E M ;{ }^{*} p<$ $0.05 ;{ }^{* *} p<0.01$ (Student's $t$ test).

every day ( $\pm 60 \mathrm{~min}$ ) for $2-4 \mathrm{~d}$ before bead injections to establish "baseline" IOP readings and then for the $7 \mathrm{~d}$ following the bead injections (at which time the animal was killed for analysis). Mice that showed no elevation in IOP after bead injection (likely due to leakage of the beads) were excluded from the study. No differences were noted in IOP readings according to the age and/or strain of mice used.

Cell fills. Intracellular dye filling of single ganglion cells was performed using methods described in detail previously (Beier et al., 2013; Dhande et al., 2013; Cruz-Martín et al., 2014; Fig. 2). Briefly, mice were anesthetized with isoflurane and the eyes were enucleated. The retinas were dissected and kept in an oxygenated $\left(95 \% \mathrm{O}_{2} / 5 \% \mathrm{CO}_{2}\right)$ solution of Ames' 

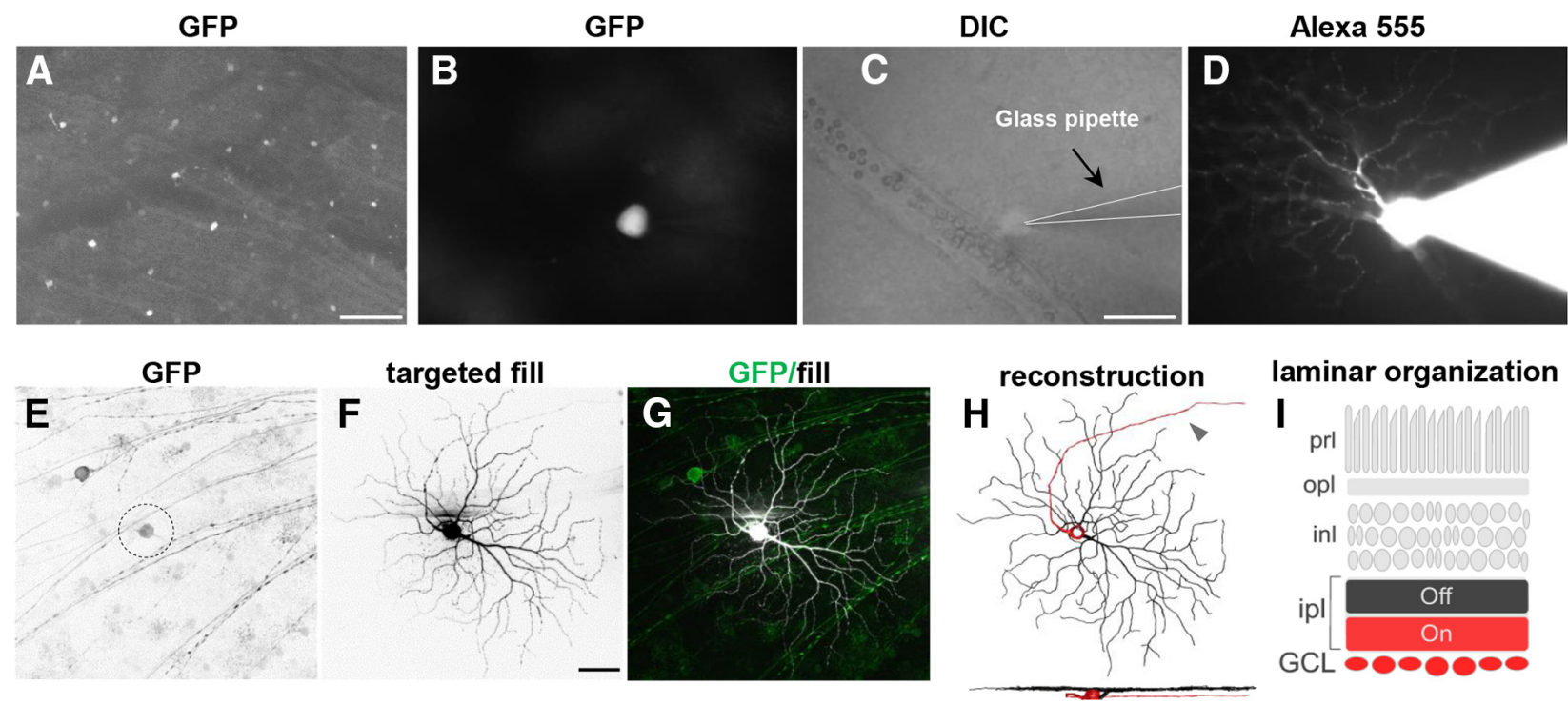

laminar organization

J

Hoxd10 (On-DSGCs)

K

Hoxd10 (aOn-Off DSGCs)
L

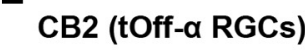

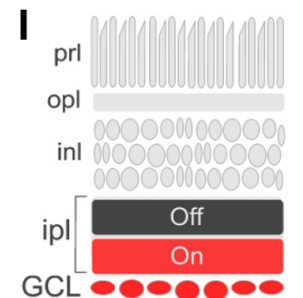
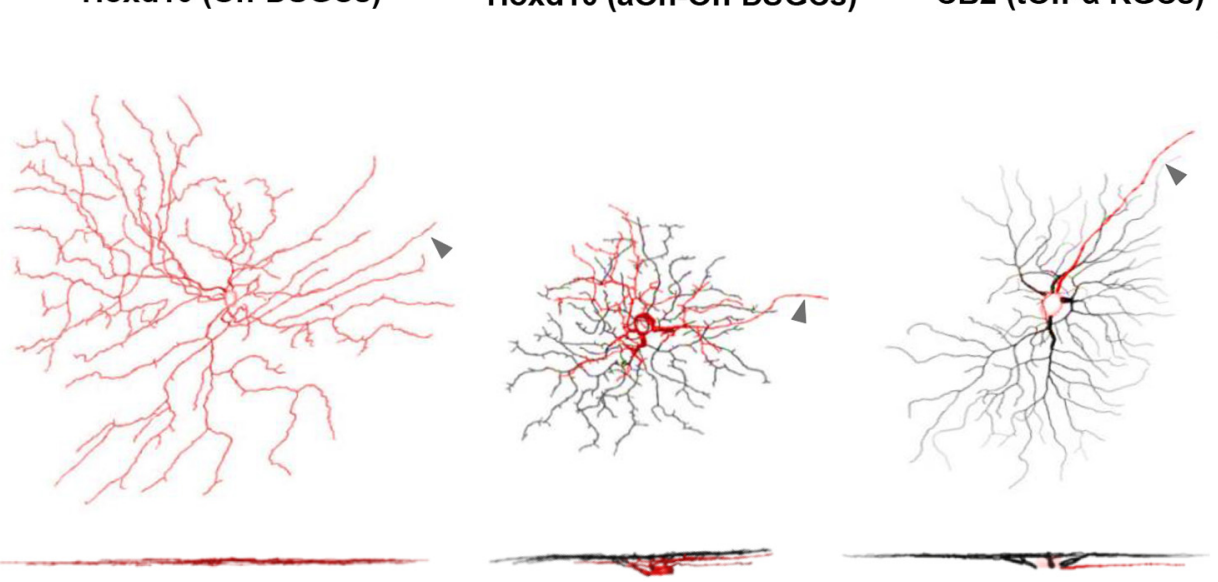

\section{M}

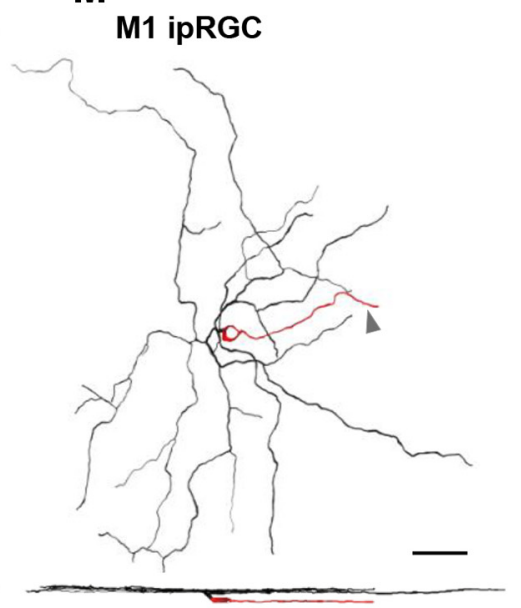

Figure 2. Transgenic mouse lines for examination of the effects of elevated IOP on specific, distinct subtypes of RGCs. $\boldsymbol{A}$, Whole-mount retina, with GFP-expressing RGCs. Scale bar, $100 \mu \mathrm{m}$. $\boldsymbol{B}-\boldsymbol{D}$, Individual GFP-expressing RGCS $(\boldsymbol{B})$ targeted with a glass pipette $(\boldsymbol{C})$ and filled with fluorescent dye to reveal its complete dendritic structure (D). Scale bar: (in $\boldsymbol{C}) \boldsymbol{B}-\boldsymbol{D}, 50 \mu \mathrm{m}$. $\boldsymbol{E}-\boldsymbol{H}, \mathrm{Maximum}$ intensity projection images showing the morphology of an individual RGC that was GFP+ $(\boldsymbol{E})$ and filled with Alexa Fluor $555(\boldsymbol{F})$. $\boldsymbol{G}$, Merged image. Green, GFP; white, targeted fill. $\boldsymbol{H}$, Neurolucida three-dimensional reconstruction of cell body, proximal axon, dendritic branching, and stratification depth. $I$, Schematic of laminar organization of the retina. The vitreal or "On sublamina" half of the inner plexiform layer (ipl) is shown in red. The scleral "Off sublamina" half of the ipl is in black. prl, photoreceptor layer; opl, outer plexiform layer; inl, inner nuclear layer; GCL, ganglion cell layer. $J-M$, Lucida reconstructions of representative examples of each of the RGC subtypes examined in this study: $0 n$ DSGCS $(\boldsymbol{J})$ and a0n-0ff DSGC $(\boldsymbol{K})$ labeled in Hoxd10-GFP transgenic mice; t0ff- $\alpha$ RGCS ( $\boldsymbol{L}$ ) labeled in CB2-GFP transgenic mouse mice; and type-M1 ipRGCS $(\boldsymbol{M})$ visualized through immunostaining with anti-melanopsin antibodies. Dendritic stratification patterns are shown below as side-view images (red: soma, axon, and dendrites localized to 0 n sublamina; black: dendrites localized to the Off sublamina). Arrowheads in $\boldsymbol{H}$ and $\boldsymbol{J}-\boldsymbol{M}$ indicate the axon (red). Scale bar, $50 \mu \mathrm{m}$.

medium (Sigma-Aldrich, catalog \#A1420) supplemented with $23 \mathrm{~mm}$ $\mathrm{NaHCO}_{3}$. GFP+ RGCs were visualized under epifluorescence, and then targeted and filled under differential interference contrast (DIC) with electrodes made with borosilicate glass (Sutter Instruments; $15-20 \mathrm{M} \Omega$ ) containing a $10 \mathrm{~mm}$ solution of Alexa Fluor 555 hydrizide (Invitrogen, catalog \#A20501MP) in $200 \mathrm{~mm} \mathrm{KCl}$. Hyperpolarizing current pulses ranging between 0.1 and $0.9 \mathrm{nA}$ were applied for $1-5 \mathrm{~min}$ to obtain a complete cell fill, which was assessed by visualization of the axon, soma, and filling of fine distal dendritic processes. The central-peripheral location of each filled neuron was tracked. To control for possible eccentricity effects, we normalized the height and width of each retina as a percentage value, and the location of each individual filled neuron was recorded as a coordinate value relative to the optic nerve head (e.g., the nerve head: $0,0)$. Only the neurons that were located within the central $30-70 \%$ of the retina were included in this study.

Retinal histology. After the completion of cell filling, the retinas were fixed for $1 \mathrm{~h}$ in $4 \%$ paraformaldehyde (PFA), then washed with $1 \times$ PBS and incubated for $1 \mathrm{~h}$ in a blocking solution consisting of $10 \%$ goat serum or $10 \%$ donkey serum, with $0.25 \%$ Triton- $\mathrm{X}$, at room temperature. The retinas were then incubated for $1-3 \mathrm{~d}$ at $4^{\circ} \mathrm{C}$ with the following primary antibodies diluted in blocking solution: rabbit anti-GFP [1: 1000; Invitrogen, catalog \#A6455; Research Resource Identifier (RRID): AB_221570], guinea pig anti-VAChT (1:1000; Millipore, catalog \#AB1588; RRID: AB_2187981), and goat anti-ChAT (1:100; Millipore, catalog \#AB144P; RRID: AB_2079751). To reveal the morphology of the M1 ipRGCs (Berson et al., 2010), some retinas were stained for melanop$\sin$ (1:1000 rabbit anti-melanopsin; Advanced Targeting Systems, catalog \#AB-N39; RRID: AB_1608076). Retinas were rinsed with PBS $(3 \times, 30$ min each), and incubated for $2 \mathrm{~h}$ at room temperature with the following secondary antibodies: Alexa Fluor 488 goat anti-rabbit (1:1000; Life Technologies, catalog \#A11034; RRID: AB_10562715), Alexa Fluor 647 goat anti-guinea pig (1:1000; Invitrogen, catalog \#A21450; RRID: AB_141882), Alexa Fluor 594 goat anti-rabbit (1:1000; Life Technologies, catalog \#A11037; RRID: AB_10561549), Alexa Fluor 647 donkey anti-goat (1:1000; Life Technologies, catalog \#A21447; RRID: AB_10584487), Alexa Fluor 488 donkey anti-rabbit (1:1000; Invitrogen, 
catalog \#A21206; RRID: AB_141708), and Alexa Fluor 647 donkey antiguinea pig (1:1000; Jackson ImmunoResearch, catalog \#706-606-148). Sections were rinsed with PBS $(3 \times, 30$ min each) and mounted onto glass slides and coverslipped with either Prolong Gold containing DAPI (Invitrogen, P36931) or Vectashield containing DAPI (Vector Laboratories, catalog \#H-1200).

Brain histology to analyze RGC axonal projections. Brains were dissected, fixed overnight with 4\% PFA, and then transferred to a $30 \%(\mathrm{w} / \mathrm{v})$ sucrose solution. Using a freezing sliding microtome, brain slices were collected at $40-45 \mu \mathrm{m}$ in the coronal plane, and immunostained for GFP using the methods described above. Sections were mounted onto glass slides and coverslipped with Vectashield containing DAPI.

Imaging. All RGCs were imaged with a laser scanning confocal microscope (Zeiss LSM 710 or 780). Image stacks were collected using a LD C-Apochromat $40 \times / 1.1$ water-immersion objective lens, with a $Z$-step increment size of $0.48-0.5 \mu \mathrm{m}$, a scanning resolution of $1024 \times 1024$ pixels, and a Kalman averaging of $2-4$.

For counting GFP + and melanopsin + cells, whole-mount images of entire retinas were acquired at $5 \times$ or $10 \times$ using a Zeiss Axio Imager 2 epifluorescence microscope equipped with an Axiocam HR camera. Using Adobe Photoshop software, the images were stitched together to include the entire retina. Brain sections containing central visual targets were acquired using a $10 \times$ objective lens.

Analysis. A total of 152 RGCs from 17 mice were analyzed for this study (72 RGCs from control eyes; 80 RGCs from eyes with elevated IOP). Complete morphological reconstructions were obtained using Neurolucida software (10.42.1, MBF Bioscience; RRID: nif-0000-10294), and analyses were performed using either Neurolucida explorer (10.42.1, MBF Bioscience) or Fiji software. A range of morphological parameters were examined, including soma diameter, total number of dendritic branches, dendritic field area (calculated by measuring the area enclosed by the outermost segments of the distal dendritic branches), dendritic length (sum of the length of the total dendritic branches), and $10 \times 10$ $\mu \mathrm{m}$ Sholl ring analysis. Dendritic orientation index (DOi) was analyzed using methods described by Krahe et al. (2011). The dendritic field of each RGC was divided into five equidistant concentric regions centered on the soma. These rings were then divided into axial planes (horizontal and vertical planes) by passing two perpendicular lines through the soma. The sum of dendritic processes crossing each of the five rings was counted within the two axial planes, and the DOi was calculated as the ratio of the minimum/maximum number of dendritic crossings in the two planes. A DOi value of 1 indicates a RGC with a radial symmetric profile.

For analysis of GFP+ cell numbers, the total number of GFPexpressing RGCs in each whole-mount retina was measured, and for each animal the normalized fraction of GFP + RGCs between the control retina and the IOP-elevated retina from the same animal was calculated and averaged. Since the total number of GFP + cells was not statistically different between the two eyes of nonbead-injected mice, this approach controlled for any variation in GFP + cell numbers that might occur between different transgenic mice. Counts were performed by three independent observers.

The dendritic change index (DCI) quantified changes in the dendritic length of the Off dendrites. We selected this parameter because it was most affected by elevated IOP. The DCI was defined as the ratio of the total dendritic length of the Off arbor in the elevated IOP condition for a cell of a given subtype [e.g., transient Off $\alpha$ (tOff- $\alpha$ ) RGCs] to the population mean dendritic length of the Off arbor under control conditions for the same subtype. Since, the On direction-selective ganglion cells (DSGCs) showed no changes in their dendritic parameters after IOP elevation, they were excluded from this analysis (see Results).

Statistical significance was assessed using two-tailed unpaired Student's $t$ test. Statistical significance of $p<0.05$ was chosen. Error bars shown in graphs represent the SEM.

\section{Results}

Application of the bead occlusion model of glaucoma in mice Here we applied the microbead occlusion animal model of glaucoma, which mimics many of the key features of elevated tension glaucoma in humans (Sappington et al., 2010; Chen et al., 2011). We injected 1-3 $\mu$ l of 10- $\mu \mathrm{m}$-diameter microbeads into the anterior chamber of the eye, where they accumulated along the ciliary margin (Fig. $1 A, B$ ). This created a physical blockage of the normal outflow of the aqueous humor through the trabecular meshwork, and caused IOP to increase in the period following the bead injection (Fig. 1C,D; Sappington et al., 2010; Chen et al., 2011). One eye was injected with microbeads. The other eye served as an internal control by receiving either no injection (corneal puncture alone) or an injection of saline (Fig. $1 A, B$; see Materials and Methods). Pressures in both eyes of each animal were monitored daily using a hand-held tonometer (see Materials and Methods). Figure $1 C$ displays the maximum IOP values from the control and two bead-injected groups. Across the population of mice studied ( $N=17$ mice) the maximum IOPs of the bead-injected eyes were significantly greater than both the baseline (preinjected) values and the values for the control eyes (Fig. $1 C ; p<0.001)$. These results are in agreement with earlier reports using this model that microbead injection is a reliable way to elevate IOPs in mice (Sappington et al., 2010; Chen et al., 2011).

We found that the mean maximum IOP for the control retinas that had corneal puncture alone versus the control retinas that received injections of $1 \mu \mathrm{l}$ saline eyes was not significantly different before or after injection (Fig. 1C; baseline maximum IOP: corneal puncture, $12.74 \pm 2.04 \mathrm{mmHg}$; saline injected, $10.86 \pm$ $0.96 \mathrm{mmHg} ; p=0.12$; postinjection maximum IOP: corneal puncture, $13.04 \pm 1.7 \mathrm{mmHg}$; saline injected, $12.00 \pm 0.90$ $\mathrm{mmHg} ; p=0.06)$. Thus data from these groups were combined into a single control group for all subsequent analysis. In addition, the mean IOP of the eyes injected with 2-3 $\mu$ l beads and the eyes injected with $1 \mu$ l beads were also not significantly different from one another and thus data from these groups were combined and referred to as the "IOP-elevated" group in subsequent analyses (preinjection maximum IOP: 2-3 $\mu$ l bead-injected eyes, $11.48 \pm 1.6 \mathrm{mmHg} ; 1 \mu \mathrm{l}$ bead-injected eyes, $11.5 \pm 2.83 \mathrm{mmHg}$; $p=0.26$; postinjection maximum IOP: $2-3 \mu$ l bead-injected eyes, $20.37 \pm 0.37 \mathrm{mmHg} ; 1 \mu \mathrm{l}$ bead-injected eyes, $19.85 \pm 0.75$ $\mathrm{mmHg} ; p=0.18$ ).

We also analyzed the time course of IOPs in the control versus bead-injected (IOP-elevated) groups (Fig. 1D). Before bead injection, IOPs were comparable between the two eyes (Fig. 1D) but by $1 \mathrm{~d}$ after bead injection (Fig. $1 D$, arrow at time point " 0 "), there was a steady increase in the IOP of the bead-injected eyes. The mean pressure of the bead-injected eyes over the first week was $15.09 \pm 0.42 \mathrm{mmHg}$, which is significantly greater than the average value at baseline for either group $(p<0.0001$; Student's $t$ test; Fig. $1 D$ ). By contrast, the IOP of the control eye did not vary significantly from prepuncture/saline injection baseline (mean pressure, $10.64 \pm 0.26 \mathrm{mmHg} ; p=0.41$; Fig. $1 D)$.

\section{Targeting of transgenically labeled RGC subtypes}

We next applied the bead occlusion model to two different transgenic mouse lines, each of which expresses GFP in 1-2 distinct RGC subtypes (Table 1). The GFP+ somas of these RGCs are readily visible in live explanted, nonimmunostained retinas (Fig. $2 A, B)$, allowing them to be targeted in live retinal explants for intracellular filling to reveal their complete somatic and dendritic morphology (Fig. 2C-G). In some animals, we also used melanopsin immunostaining, which selectively labels M1-type and M2-type ipRGCs (Table 1; Berson et al., 2010). However, we only focused on M1 ipRGCs because their complete somatic and dendritic morphologies can be revealed by melanopsin staining (Ber- 
son et al., 2010). For all the experiments described below, retinas were harvested $7 \mathrm{~d}$ after microbead injection.

After filling and staining, we imaged the RGCs using confocal microscopy and generated three-dimensional reconstructions of their dendritic arbors using Neurolucida software (Fig. 2E-H). Sample en face morphologies and side views of each of the RGC subtypes examined in this study are shown in Figure $2 J-M$. The somas, axons, and the portion of the dendritic arbors stratifying in the inner (vitreal) half of the inner plexiform layer (IPL) are shown in red, and dendrites stratifying in the outer (scleral) portion of the IPL is shown in black (Fig. $2 H-M$; see Materials and Methods). Notably, the subtypes examined here cover a wide range of sizes, shapes, and arbor complexities (Fig. 2J-M). Some mouse RGC subtypes are reported to display size differences as a function of eccentricity or retinal quadrant (Bleckert et al., 2014). Therefore, we restricted our analysis to RGCs filled from the middle portions ( $30-70 \%$ eccentricity) of the retina (see Materials and Methods).

\section{Transient Off- $\alpha$ RGCs undergo rapid, ocular-pressure- induced shifts in dendritic symmetry}

To investigate for anatomical changes in RGCs at early stages after elevated IOP, we began by analyzing the structure of the tOff- $\alpha$ RGCs, the RGC subtype expressing GFP in CB2-GFP mice (Table 1; Huberman et al., 2008). These RGCs have large somas, medium-sized dendritic fields, and radially organized dendrites that monostratify in the Off sublamina of the IPL (Figs. $2 L, 3 A-$ C,O; Pang et al., 2003; Huberman et al., 2008). After $7 \mathrm{~d}$ of elevated IOP, the GFP-expressing tOff- $\alpha$ RGCs were targeted and filled, and their morphology examined. In bead-injected retinas, the cell bodies of tOff- $\alpha$ RGCs showed no apparent size changes (Fig. 3G; control diameter, $23.86 \pm 0.64 \mu \mathrm{m}$; IOP-elevated diameter, $23.59 \pm 0.83 \mu \mathrm{m} ; p=0.79)$. Overall dendritic branch numbers were also similar to controls (Fig. $3 \mathrm{H}$; control, $131.65 \pm 4.58$; IOP elevated, $118.42 \pm 9.13 ; p=0.19 ; n=26$ control $n=24$ IOP elevated; $N=6$ mice).

Major differences were observed, however, between tOff- $\alpha$ RGCs from control and bead-injected eyes. First, the dendritic length of tOff- $\alpha$ RGCs from IOP-elevated eyes was significantly reduced (Fig. 3I; controls, $4499.86 \pm 194.65 \mu \mathrm{m}$; IOP elevated, $3708.79 \pm 277.66 \mu \mathrm{m} ; p<0.05$ ), as was dendritic field area (Fig. 3J; controls, 50,450.74 $\pm 3813.98 \mu \mathrm{m}^{2}$; IOP elevated, 34,533.08 \pm $\left.4118.38 \mu \mathrm{m}^{2} ; p<0.01\right)$.

Notably, some tOff- $\alpha$ RGCs from IOP-elevated eyes had highly asymmetric profiles compared with the radial geometry of tOff- $\alpha$ RGCs typical of controls (Fig. 3, compare $C$ and F, $O$ and $P$ ). This shift toward asymmetry was also readily apparent from Sholl analysis, which quantifies dendritic field size and complexity as a function of distance from the soma (Fig. $3 \mathrm{~K}$ ), and also from analysis of dendritic orientation (Fig. $3 L-N$; control DOi, $0.85 \pm 0.03$; IOP-elevated DOi, $0.68 \pm 0.04 ; p<0.01$; Krahe et al., 2011; see Materials and Methods). To investigate whether there was a directional bias to this change in dendritic symmetry, the orientation of a subset of tOff- $\alpha$ RGCs $(n=13)$ was tracked according to retinal quadrant. In cases where there was a marked dendritic shift, it consistently occurred in the direction away from the temporal quadrant (Fig. 4A). These changes did not reflect IOP-induced shifts in transgene expression as the axonal projections of CB2-GFP RGCs were similar between control and IOP-elevated neurons: they projected to the same two targets, the superior colliculus (SC) and dorsal lateral geniculate nucleus (LGN), and only to those targets (Fig. $4 B-E$ ). The GFP+ axons from control and IOP-elevated eyes also were directed to the same sublaminar zones within those targets: the lower stratum griseum superficialis of the SC (Huberman et al., 2008) and the "core" of the dorsal LGN (Huberman et al., 2008; Krahe et al., 2011; Dhande and Huberman et al., 2014). This supports the conclusion that the GFP+ RGCs in both experimental groups consisted of the same RGC subtype: tOff- $\alpha$ RGCs (Fig. $4 B-E$; Huberman at al., 2008). Collectively, these results demonstrate that just $7 \mathrm{~d}$ of elevated IOP causes tOff- $\alpha$ RGC dendrites to undergo significant rearrangements, including shrinkage of their overall arbors within the Off sublamina of the IPL.

\section{On DSGCs are structurally resistant to the early phase of elevated intraocular pressure}

Next we examined the morphology of the On DSGCs (in Hoxd10-GFP mice). In both control and IOP-elevated retinas, these cells had large, monostratified dendritic fields that were restricted to the vitreal or On sublayer of the IPL, although it is worth noting that mouse On DSGCs often have a small portion $(\sim 12 \%)$ of their dendritic arbor within the Off sublamina (Dhande et al., 2013), which we observed here (Fig. 5A-C, K, M). Of the On-DSGC features we examined (soma size, dendritic branch number, field, length or patterns of branching), none of them differed significantly between control and IOP-elevated retinas (Fig. $5 G-L ; p>0.16$ in all cases; $N=6$ mice; $n=15$ RGCs from control eyes; $n=18$ RGCs from elevated-IOP eyes). Since the GFP-expressing RGCs in Hoxd10-GFP mice include all three subtypes of On DSGCs (Dhande et al., 2013), we conclude that the somas and dendrites of On DSGCs appear structurally unaffected during the first week following bead-elevated IOP.

\section{Bidirectional dendritic rearrangements in anterior-tuned On-Off DSGCs caused by elevated IOP}

Next we examined the anterior-tuned On-Off DSGCs (aOn-Off DSGCs) labeled in Hoxd10-GFP mice. These neurons are characterized by small dendritic fields that normally stratify $\sim 60 \%$ of their dendrites within the Off (scleral) sublamina and $\sim 40 \%$ in the On (vitreal) sublamina of the IPL (Dhande et al., 2013; Fig. $6 C, K)$. We found no significant differences in the soma diameter or total dendritic length (Fig. $6 \mathrm{G}$; control mean soma diameter, $18.69 \pm 0.57 \mu \mathrm{m}$; mean diameter of IOP-elevated eye, $18.15 \pm$ $0.68 \mu \mathrm{m} ; p=0.55 ; N=6$ mice, $n=11$ RGCs from control eyes; $n=12$ RGCs from elevated-IOP eyes; Fig. $6 \mathrm{H}$; control total dendritic length, $2821.05 \pm 179.73 \mu \mathrm{m}$; dendritic length of IOPelevated eye, $4053.05 \pm 108.74 \mu \mathrm{m} ; p=0.23)$. The overall number of dendritic branches, however, was significantly increased in the bead-injected retinas (Fig. 6J; $181.27 \pm 12.06$ branches in controls vs $246.67 \pm 15.52$ branches in IOP-elevated eyes; $p<0.01$ ).

Interestingly, there was a laminar specificity to this change, such that the dendritic length of On dendrites significantly increased (Fig. $6 \mathrm{~K}, L$; dendritic length for controls, $1510.13 \pm$ $173.86 \mu \mathrm{m}$; dendritic length for IOP elevated, $2191.02 \pm 234.72$ $\mu \mathrm{m} ; p<0.05)$ and Off dendrites significantly decreased compared with controls (Fig. $6 \mathrm{~K}, \mathrm{M}$; dendritic length for controls, $2285.51 \pm 146.15 \mu \mathrm{m}$; dendritic length for IOP elevated, $1823.02 \pm 227.96 \mu \mathrm{m} ; p=0.11$; Fig. 7). These differences in dendritic length were likely due to regional changes along the dendritic arbor because Sholl analysis revealed a significant increase in the number of dendritic intersections for On sublamina dendrites at 30, 40, 70, and $90 \mu \mathrm{m}$ from the soma (Fig. 6O), and reductions in Off dendrites at locations $20-30 \mu \mathrm{m}$ from the soma (Fig. 6P). We also analyzed the dendritic symmetry of Off dendrites of aOn-Off DSGCs in the two groups but saw no significant 

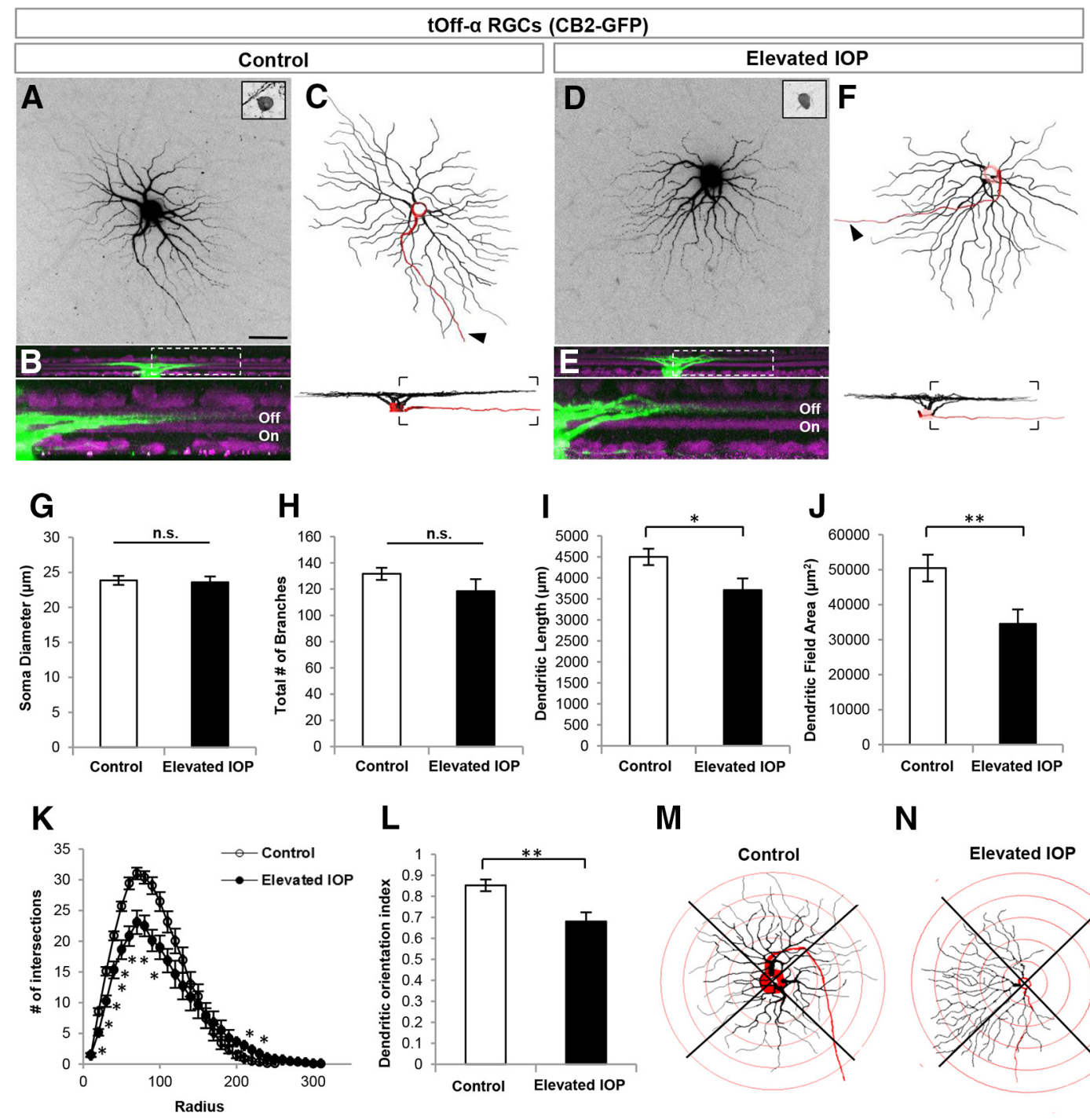

$\mathbf{L}$

M

$\mathbf{N}$
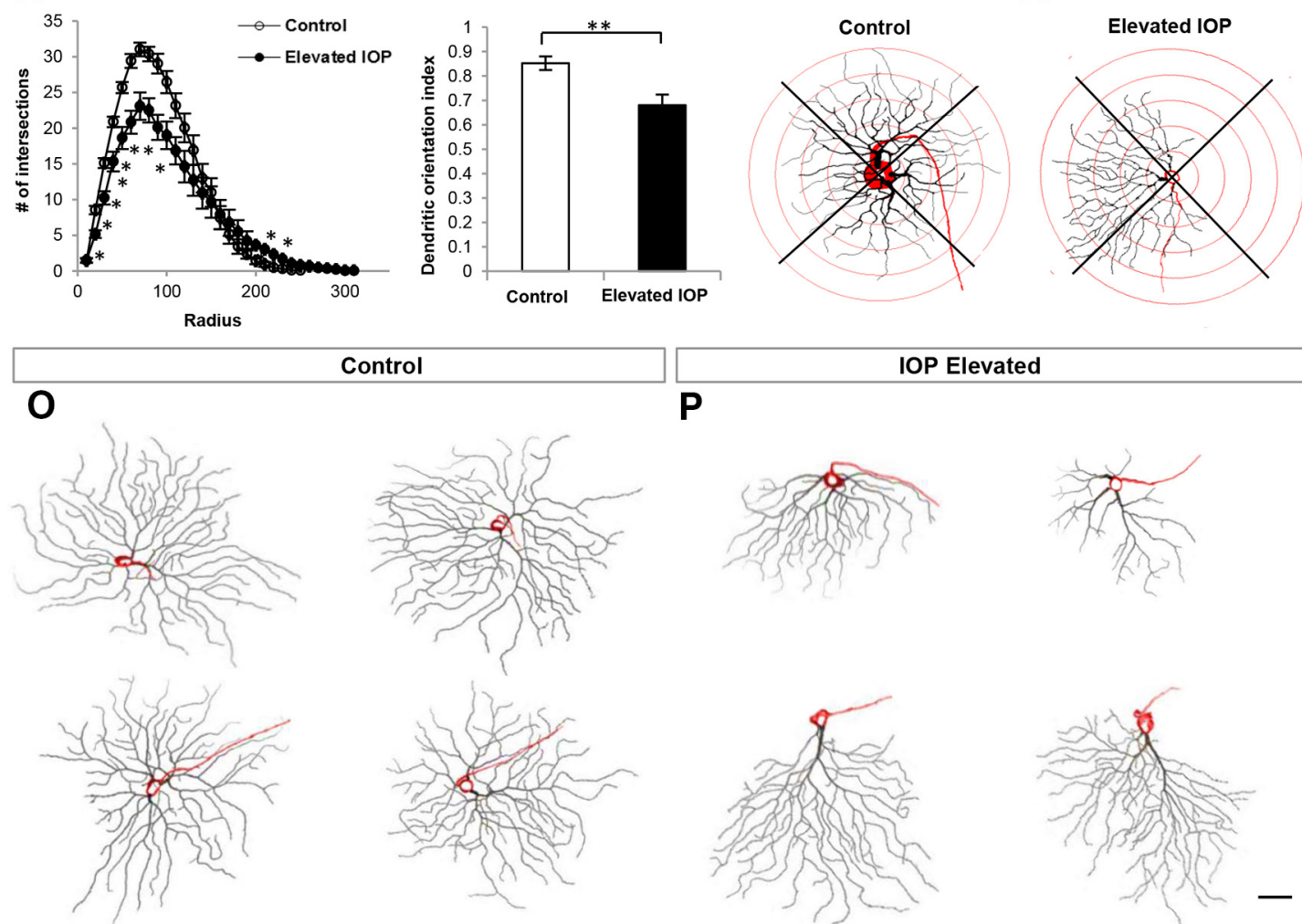

Control
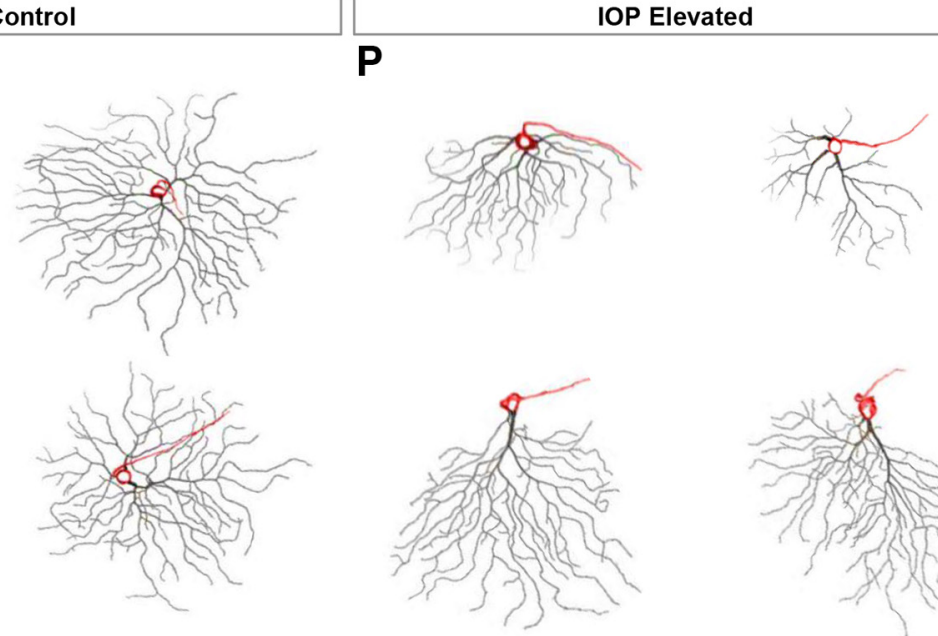

Figure 3. toff- $\alpha \mathrm{RGCS}$ rapidly alter their dendritic structure in response to elevated IOP. $A-F$, Maximum intensity projection confocal images of t0ff- $\alpha \mathrm{RCCS}$ from control $(\boldsymbol{A}-\boldsymbol{C})$ and IOP-elevated retinas ( $\boldsymbol{D}-\boldsymbol{F})$. CB2-GFP somas $(\boldsymbol{A}, \boldsymbol{D}$, inset image) were filled with Alexa Fluor 555 hydrazide dye $(\boldsymbol{A}, \boldsymbol{D})$ and reconstructed $(\boldsymbol{C}, \boldsymbol{F})$. Arrowhead, Axon. $\boldsymbol{B}, \boldsymbol{E}$, Side views showing the stratification depth of the dendritic arbor within the Off sublamina (green, cell fill; purple, ChAT and VAChT immunostaining; bottom panels show area in dotted rectangle). $G-L$, Quantification of various morphological parameters examined for RGCs in control (white bars) and IOP-elevated/bead-injected (black bars) eyes. No significant differences (n.s.) were found in soma diameter (G) and total number of

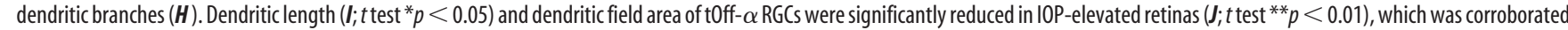
by Sholl ring analysis ( $\boldsymbol{K}$; t test statistical significance: $\left.20-90 \mu \mathrm{m},{ }^{*} p<0.001 ; 100-110 \mu \mathrm{m},{ }^{*} p<0.01 ; 210-220 \mu \mathrm{m},{ }^{*} p<0.05\right)$, and D0i analysis $\left(\boldsymbol{L},{ }^{* *} p<0.01\right) . M, N$, representative example of the Sholl ring analysis used to generate the dendritic orientations values in $\boldsymbol{L}$ for control $(\boldsymbol{M})$ and IOP-elevated neurons $(\boldsymbol{N})$. For $\mathbf{G}-\boldsymbol{L}$, error bars represent \pm SEM; $\mathbf{0}, \boldsymbol{P}$, Examples of tOff- $\alpha$ RGCS obtained from control retinas $(\mathbf{O})$ and IOP-elevated retinas $(\boldsymbol{P})$. Side views shown at the bottom of each neuron (red: soma and axon; black: Off sublamina dendrites). Scale bars: $\boldsymbol{A}, \boldsymbol{P}, 50 \mu \mathrm{m}$. 
A
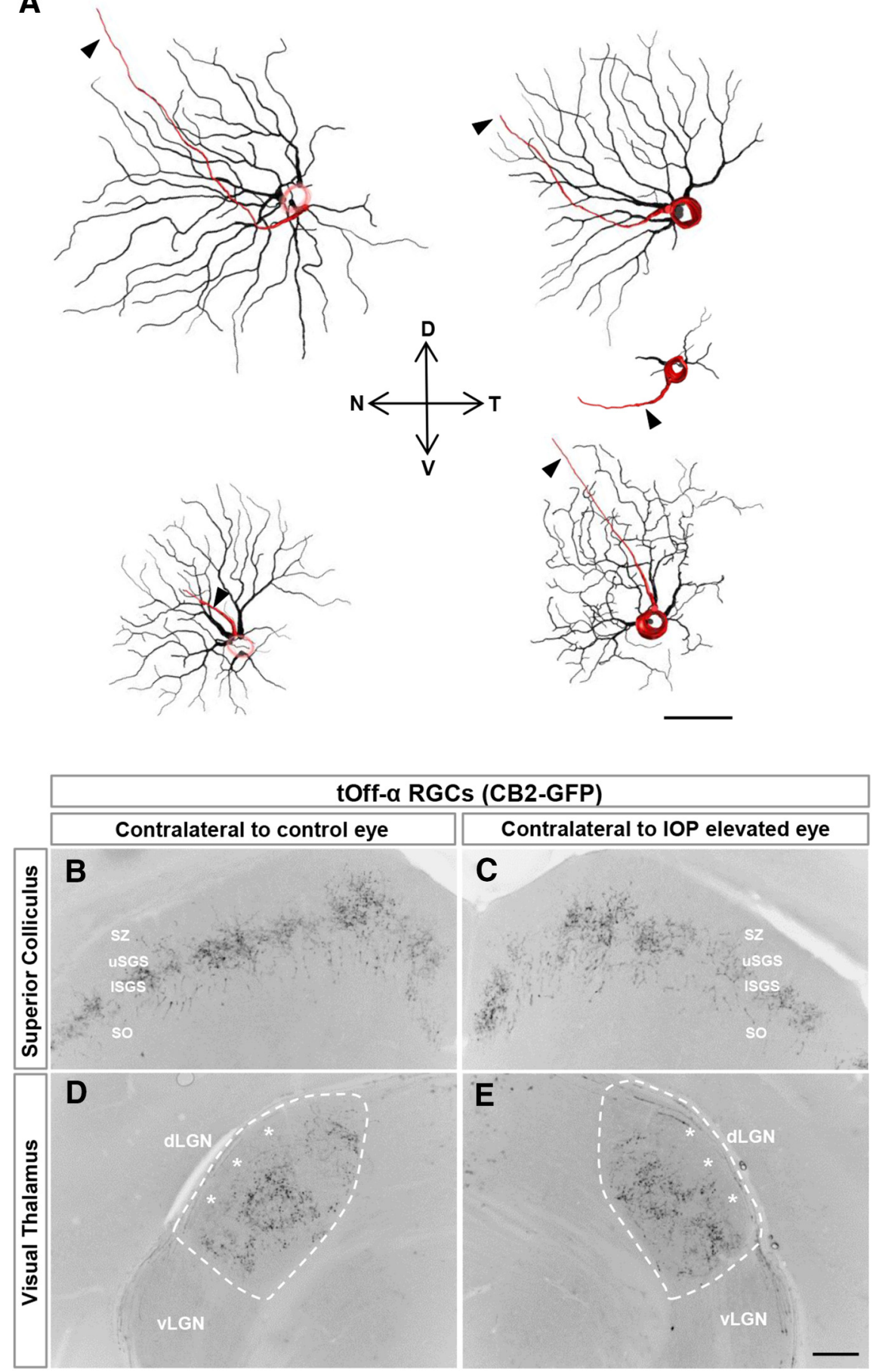

Figure 4. Change in symmetry of t0ff- $\alpha \mathrm{RGCs}$ is not due to changes in GFP expression patterns. $A$, Neurolucida reconstructions of tOff- $\alpha$ RGCs in CB2-GFP mice showing asymmetric morphologies. For most cells, the dendrites are pointed away from the temporal axis. D, dorsal; $N$, nasal; T, temporal; $V$, ventral. Scale bar, $50 \mu \mathrm{m}$. $\boldsymbol{B}-\boldsymbol{E}$, Axonal projections patterns of t0ff- $\alpha \mathrm{RGCs}$ are maintained to and within central visual targets after IOP elevation, indicating that there is no change in the GFP expression patterns caused by the bead injections. dLGN, dorsal LGN; vLGN, ventral LGN; SO, stratum optimum; ISGS, lower stratum griseum superficialis; USGS, upper stratum griseum superficialis; $S Z$, stratum zonale. $D, E$, dashed line delineates the border of the dLGN. Asterisks indicate the shell of the dLGN, which is devoid of CB2-GFP axonal projections (Huberman et al., 2008, 2009). Scale bar, $100 \mu \mathrm{m}$.

differences (DOi for controls, $0.69 \pm 0.07$; DOi for IOP elevated, $0.67 \pm 0.07 ; p=0.86)$.

To address the possibility that the apparent increase in On dendrites was because bead injections somehow reduced On arbors in the control eye (between-eye effects). We compared the dendritic length of On arbors and field area in aOn-Off DSGCs in naive untreated retinas versus control retinas and saw no differences between these groups. These values were consistent with those reported previously for the proportion of On-arbor size in these cells (Dhande et al., 2013). Thus, the increase in On arbors in bead-injected eyes reflects changes induced by elevated IOP (dendritic length of On arbors: naive, $1355 \pm 244.77 \mu \mathrm{m} ; p=$ 0.62 compared with controls; $p<0.05$ compared with IOP elevated; Fig. 6I; dendritic field: naive, 25,892.04 $\pm 2345.4 \mu \mathrm{m}^{2}$; controls, 26,286.89 $\pm 2141.16 \mu \mathrm{m}^{2}$; IOP elevated, $29,616.57 \pm 2649.28 \mu \mathrm{m}^{2} ; p>0.34$ for all cases).

Together, these data indicate that, after brief exposure to elevated IOP, aOn-Off DSGCs undergo significant dendritic remodeling involving a reduction in the dendrites targeted to the Off sublamina and an increase in the length of dendrites targeted to the On sublamina of the IPL (Fig. 7).

\section{M1 ipRGCs: On-type RGCs with Off- stratifying dendrites that rearrange in glaucoma}

Thus far, we observed a pattern in which Off dendrites of tOff- $\alpha$ RGCs and aOnOff DSGCs undergo a reduction in area and/or length, whereas On dendrites exhibit either no change (On DSGCs) or an overall expansion (aOn-Off DSGCs). Is there something structurally important about the Off sublayer that makes dendrites stratifying at this IPL depth more vulnerable to loss under conditions of elevated IOP or is it the functional attributes of Off-type connections that occur at this IPL depth that are relevant? M1 ipRGCs provide a unique way to address this question because, functionally, M1s are pure On-type RGCs that respond to increments in light, but their dendrites exclusively stratify in the "Off" sublayer and receive their On-bipolar input from en passant synapses (Dumitrescu et al., 2009; Zhao et al., 2014).

M1 ipRGCs have large dendritic fields that stratify near the boundary of the inner nuclear layer and IPL (Figs. $2 M, 8 A-$ $C, L$; Berson et al., 2010). Neither soma size nor dendritic field area were different for M1 ipRGCs in control versus IOPelevated retinas (Fig. 8G, $H$; $\operatorname{control} n=20$ RGCs; IOP-elevated $n=26$ RGCs, $N=7$ mice; $p>0.31$ ). We did, however, observe a significant overall reduction in the amount of dendritic branching and length in the elevated-IOP condition (Fig. 8I; total branch number: controls, $27.25 \pm 1.89$; IOP elevated, $20.62 \pm 1.7 ; p<$ 0.05; Fig. 8J; dendritic length: controls, $2102.9 \pm 145.51 \mu \mathrm{m}$; IOP elevated, $1656.51 \pm 117.55 \mu \mathrm{m} ; p<0.05)$. Such reductions appeared regionally biased along the dendritic arbor: Sholl analysis 


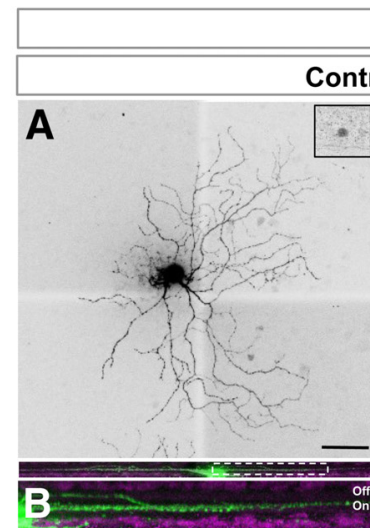

G

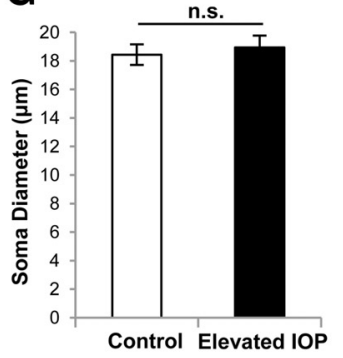

J

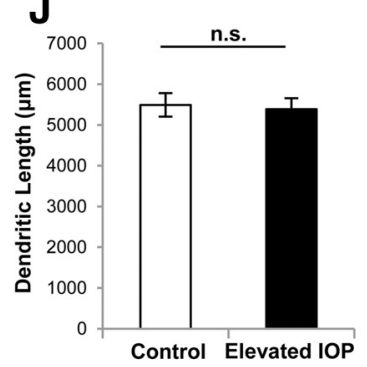

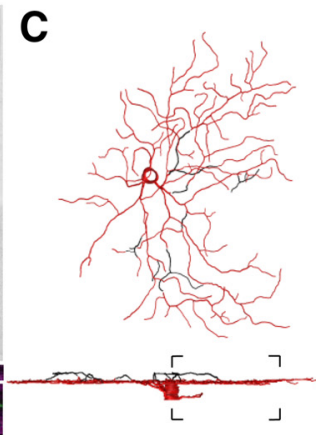

H

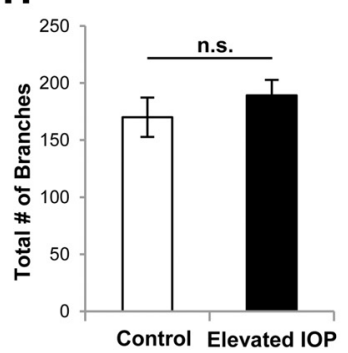

K

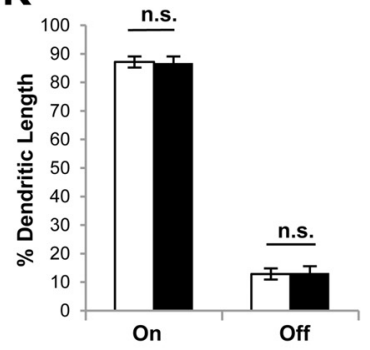

Elevated IOP
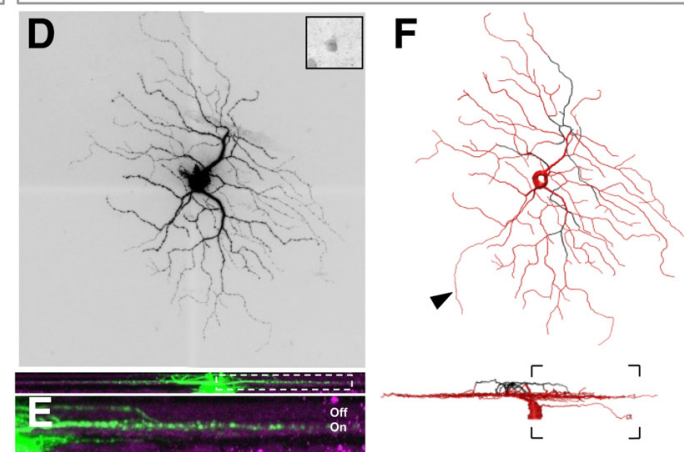

I

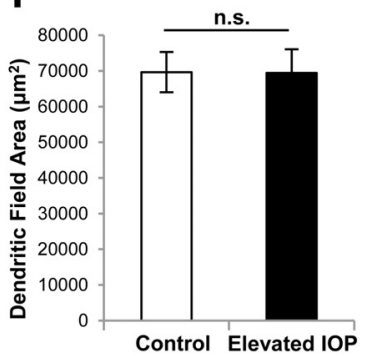

$\mathbf{L}$

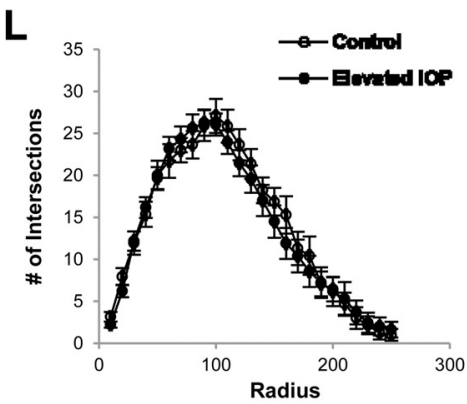

Control

M

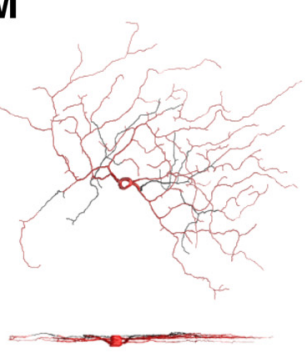

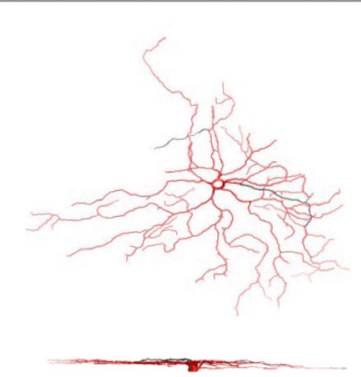

Elevated IOP

N
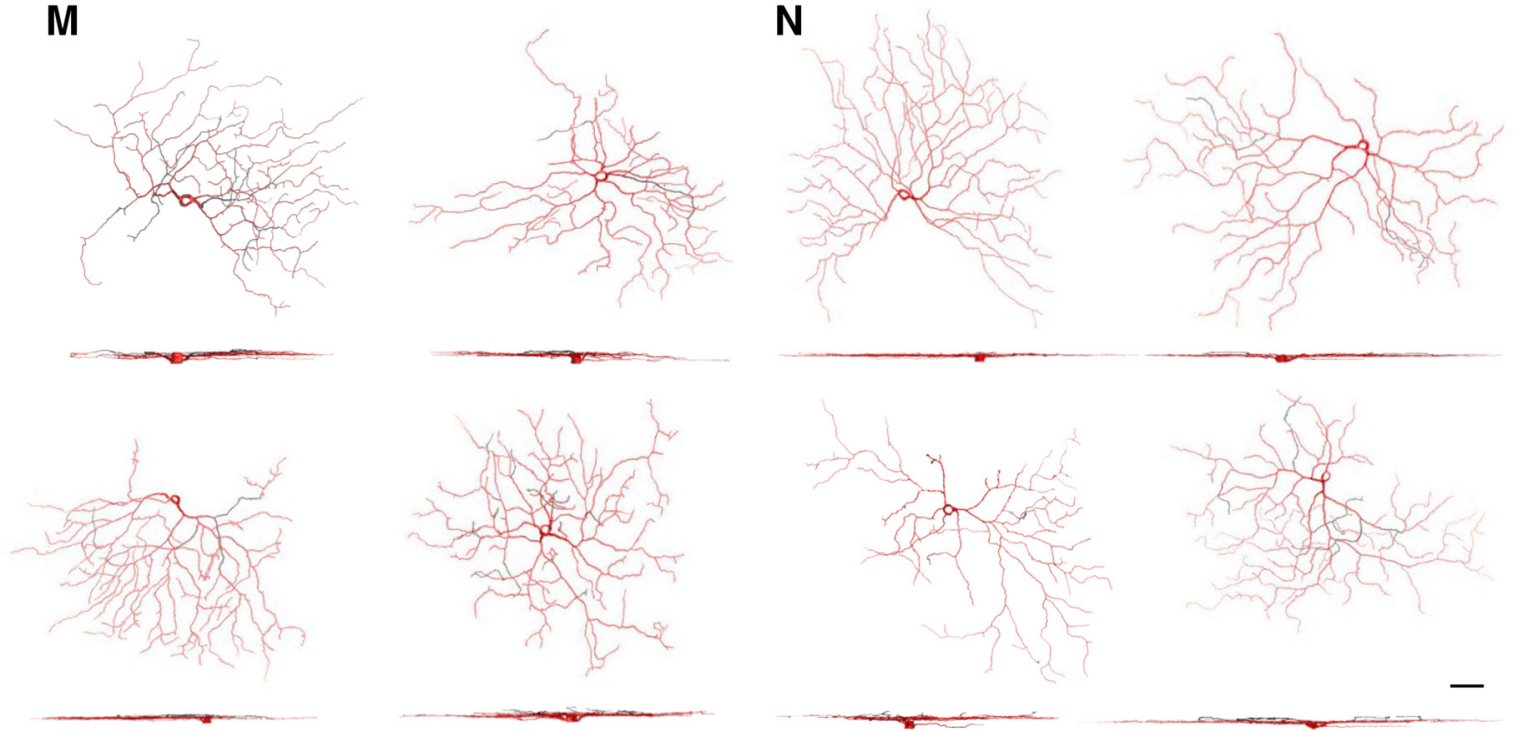

Figure 5. On DSGCS are structurally resistant to the early phase of elevated IOP. A-F, Same format as for Figure 3 but GFP cells are On DSGCs from Hoxd10-GFP mice. G-K, Quantification of various morphological parameters examined for RGS in control (white bars) and IOP-elevated (black bars) eyes. No significant differences ( $\mathrm{n} . \mathrm{s}$.) were found for any of the morphological parameters studied, including soma diameter $(\boldsymbol{G})$, total number of branches $(\boldsymbol{H})$, dendritic field area $(\boldsymbol{I})$, dendritic length $(\boldsymbol{J})$, as well as the percentage dendritic length in the 0 n versus Off sublaminae $(\boldsymbol{K})$. $\boldsymbol{L}$, Moreover, no changes were noted when examining the overall dendritic architecture using Sholl ring analysis. For $\mathbf{G}-\mathbf{L}$, error bars represent \pm SEM. $\boldsymbol{M}, \boldsymbol{N}$, Representative examples of On DSGCS in control $(\boldsymbol{M})$ and IOP-elevated retinas ( $\boldsymbol{N}$ ). For $\boldsymbol{C}$, $F, M$, and $\boldsymbol{N}$, red represents the soma, axon (arrowhead), and dendrites found in the 0 sublamina, while dendrites present in the Off sublamina are depicted in black. Scale bars: $A, N, 50 \mu \mathrm{m}$. 


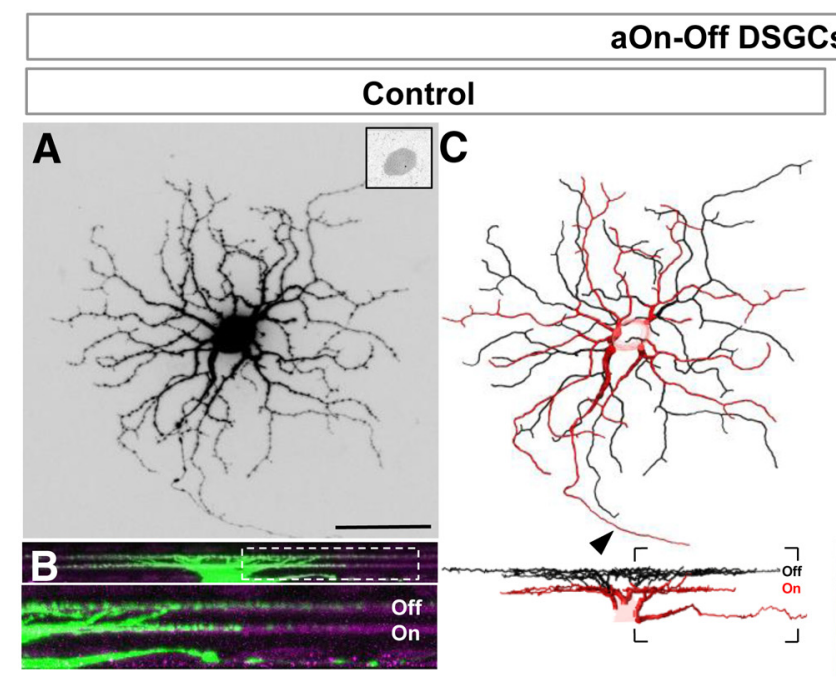

(Hoxd10-GFP)
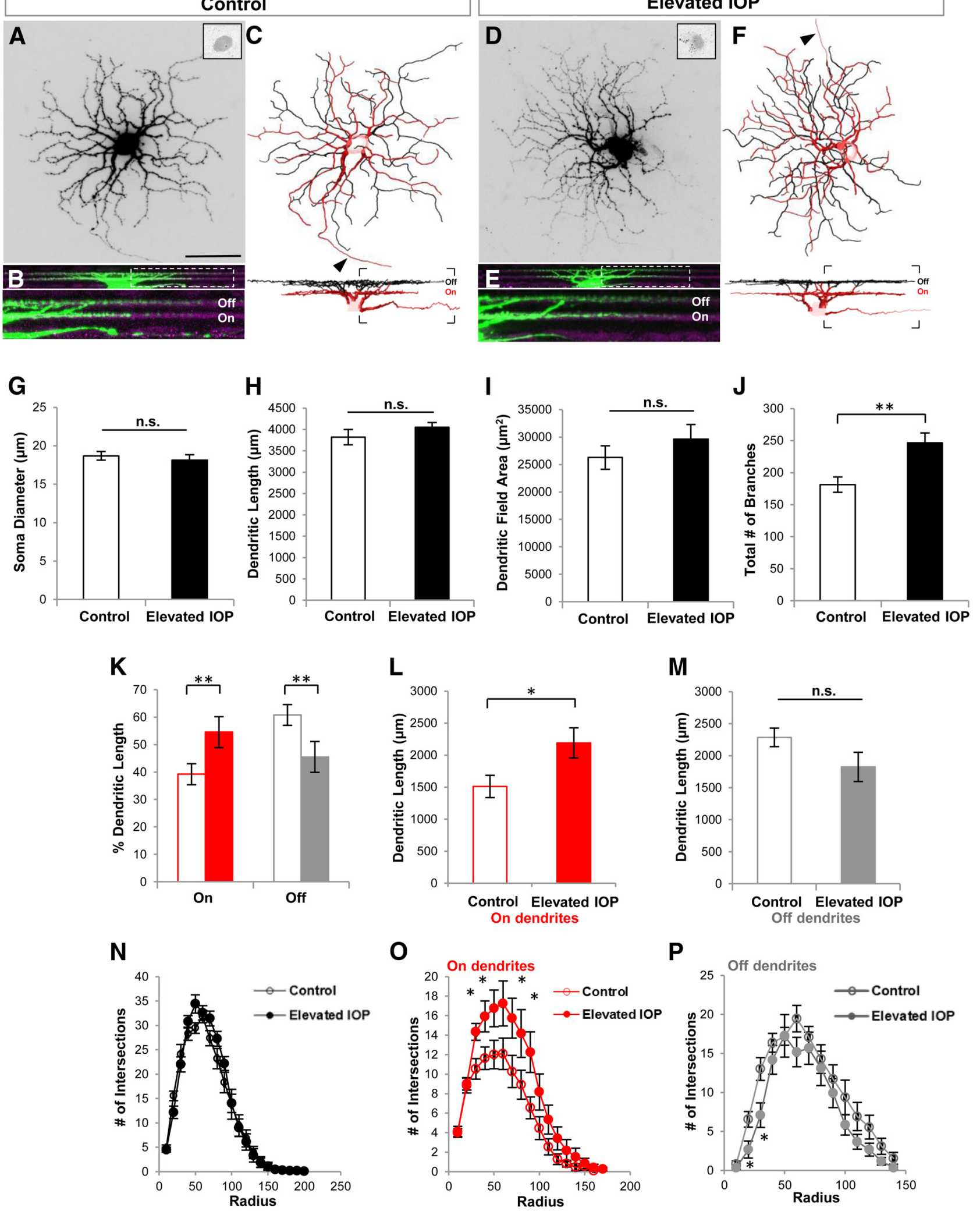

Figure 6. a0n-Off DSGCS show laminar-specific alterations in their dendritic structure. $\boldsymbol{A}-\boldsymbol{F}$, Same as in Figure 5 but for a0n-0ff DSGCs labeled in Hoxd10-GFP mice. G-I, No significant changes were noted for soma size $(\boldsymbol{G})$, dendritic length $(\boldsymbol{H})$, and dendritic field area $(\boldsymbol{I})$ of a0n-OffDSGCs in control (white bars) and IOP-elevated retinas (black bars). $\boldsymbol{J}-\boldsymbol{M}$, RGCs had a larger number of total dendritic branches $(\boldsymbol{J})$ in IOP-elevated retina, caused by an increase in the length of the dendrites present in the 0 n sublamina $(\boldsymbol{K}, \boldsymbol{L})$ and a reduction of $0 f f-$ sublamina dendrites $(\boldsymbol{K}, \boldsymbol{M})$. $\boldsymbol{N}-\boldsymbol{P}$, Sholl analysis revealing the increased branching of 0 n-sublamina dendrites $\left(\boldsymbol{O}\right.$, asterisk) and reduction of 0 ff-sublamina ones $\left(\boldsymbol{P}\right.$, asterisk). For $\mathbf{G}-\boldsymbol{P}, t$ test ${ }^{*} p<0.05$ and ${ }^{* *} p<0.01$; error bars represent \pm SEM. For $\boldsymbol{C}-\boldsymbol{F}$, the soma, axon (arrow), and 0 n dendrites are shown in red, and Off-sublamina dendrites are shown in black. Scale bar: $\boldsymbol{A}, 50 \mu \mathrm{m}$. 

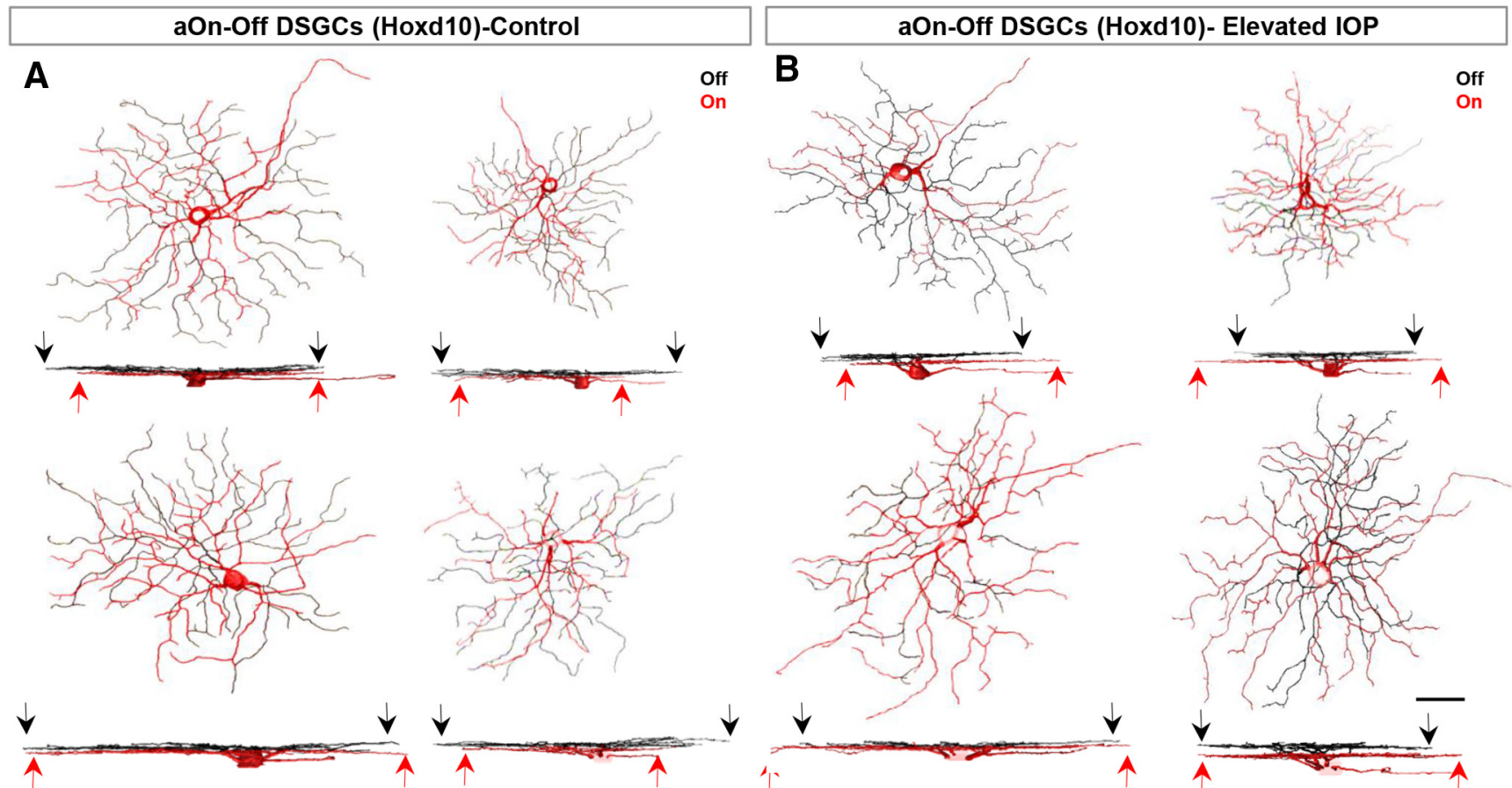

Figure 7. Additional examples of a On-OffDSGCs in Hoxd10-GFP retinas. $\boldsymbol{A}, \boldsymbol{B}, \mathrm{RGCs}$ from control retinas $(\boldsymbol{A})$ and IOP-elevated retinas $(\boldsymbol{B})$. The soma, axon, and dendrites found in the $0 \mathrm{n}$ sublamina are shown in red, while dendrites present in the Off sublamina are depicted in black. Note the increase in On-sublamina dendrites (red arrows) and the reduction in Off-sublamina dendrites (black arrows; Fig. 6). Scale bar, $50 \mu \mathrm{m}$.

revealed that elevated IOP caused significant reductions in dendritic branching at the proximal-most $(50-120,150 \mu \mathrm{m}$ from the soma) locations along the arbors of M1 ipRGCs (Fig. $8 \mathrm{~K}$ ). Thus, elevated IOP causes rapid loss of dendritic arbors for yet another cell type stratifying in the Off sublamina, even though functionally, these are On RGCs.

\section{RGC subtype-specific loss occurs in a manner predicted by dendritic changes}

Previous studies have shown using the bead occlusion model in mice that $\sim 20 \%$ of RGCs are lost after 2 weeks of IOP elevation (Chen et al., 2011). Next we sought to determine whether there is any subtype specificity to the RGC loss during the early period of IOP elevation and, if so, whether that loss was predicted by the RGC subtype-specific dendritic changes discussed above. For each transgenic line, the total number of GFP-expressing RGCs per retina was compared between control and IOP-elevated eyes at 1 or 2 weeks after IOP elevation (Fig. 9A). CB2-GFP RGCs showed the greatest reduction compared with other RGC subtypes examined; after 1 week of IOP elevation, the fraction of CB2-GFP RGCs in IOP-elevated eyes was $0.91 \pm 0.05$ of that in control CB2-GFP eyes $(N=5$ mice; $p=0.09)$ and, at 2 weeks after IOP elevation, this value was reduced to $0.77 \pm 0.08 \mathrm{com}$ pared with controls $(N=4$ mice; $p<0.01)$. Hoxd10-GFP RGCs also showed a significant and stable reduction in cell number at 1 and 2 weeks after IOP elevation ( 1 week: $0.94 \pm 0.02, N=4$ mice, $p<0.01$; 2 weeks: $0.95 \pm 0.02, N=4$ mice, $p<0.01$ ). Interestingly, no significant change was observed for the fraction of M1 ipRGCs at 1 or 2 weeks after IOP elevation, which is consistent with previous reports showing that melanopsin-expressing RGCs are less susceptible to glaucoma-induced death (1 week: $1.01 \pm$ $0.08, p=0.9, N=4$ mice; 2 weeks: $0.99 \pm 0.01, p=0.31, N=3$ mice; Li et al., 2006). Comparison between transgenic lines revealed that CB2-RGCs displayed the most significant reduction compared with all the other RGC subtypes ( $p<0.05$ compared with Hoxd10-GFP RGCs; $p<0.05$ compared with M1 ipRGCs). In our experience, even within the same strain or litter, the number of GFP-expressing cells can vary between animals. We note, however, that all the analysis of RGC number reported here reflects the fraction of GFP cells in the control versus the IOPelevated eyes of the same animal and in untreated animals the fraction of RGCs between the two eyes is not significantly different (Fig. 9B-D). Thus, we can reliably conclude that tOff- $\alpha$ RGCs are among the early cohorts of RGCs that display dendritic changes and are lost in response to IOP elevation.

\section{Lack of correlation between soma size and dendritic vulnerability in early response to IOP elevation}

Because transgenic labeling allows for quantitative analysis of various RGC characteristics related to both somatic and dendritic morphology, we asked whether there are any correlations between soma size and dendritic vulnerability to IOP elevation. To do this, we generated a DCI that takes into account the degree of change in Off dendritic length for RGCs in IOP-elevated versus control retinas (see Materials and Methods) and plotted that relative to RGC soma size (Fig. 10). We observed no significant correlation between the DCI and soma size across the RGC subtypes that altered their dendrites in response to IOP elevation (Fig. 10; linear regression: $r^{2}=0.004, p=0.23$ ), nor was there a significant correlation within tOff- $\alpha$ RGC and aOn-Off DSGC subtypes (linear regression: tOff- $\alpha$ RGCs, $r^{2}=0.11, p=0.11$; aOn-Off DSGCs, $\left.r^{2}=0.2, p=0.15\right)$. M1 ipRGCs with smaller somas were weakly correlated with increased alterations in dendritic length $\left(r^{2}=0.2, p=0.02\right)$.

\section{Discussion}

Here we investigated the early structural changes that occur in RGCs exposed to elevated IOP. Previous work using the same 

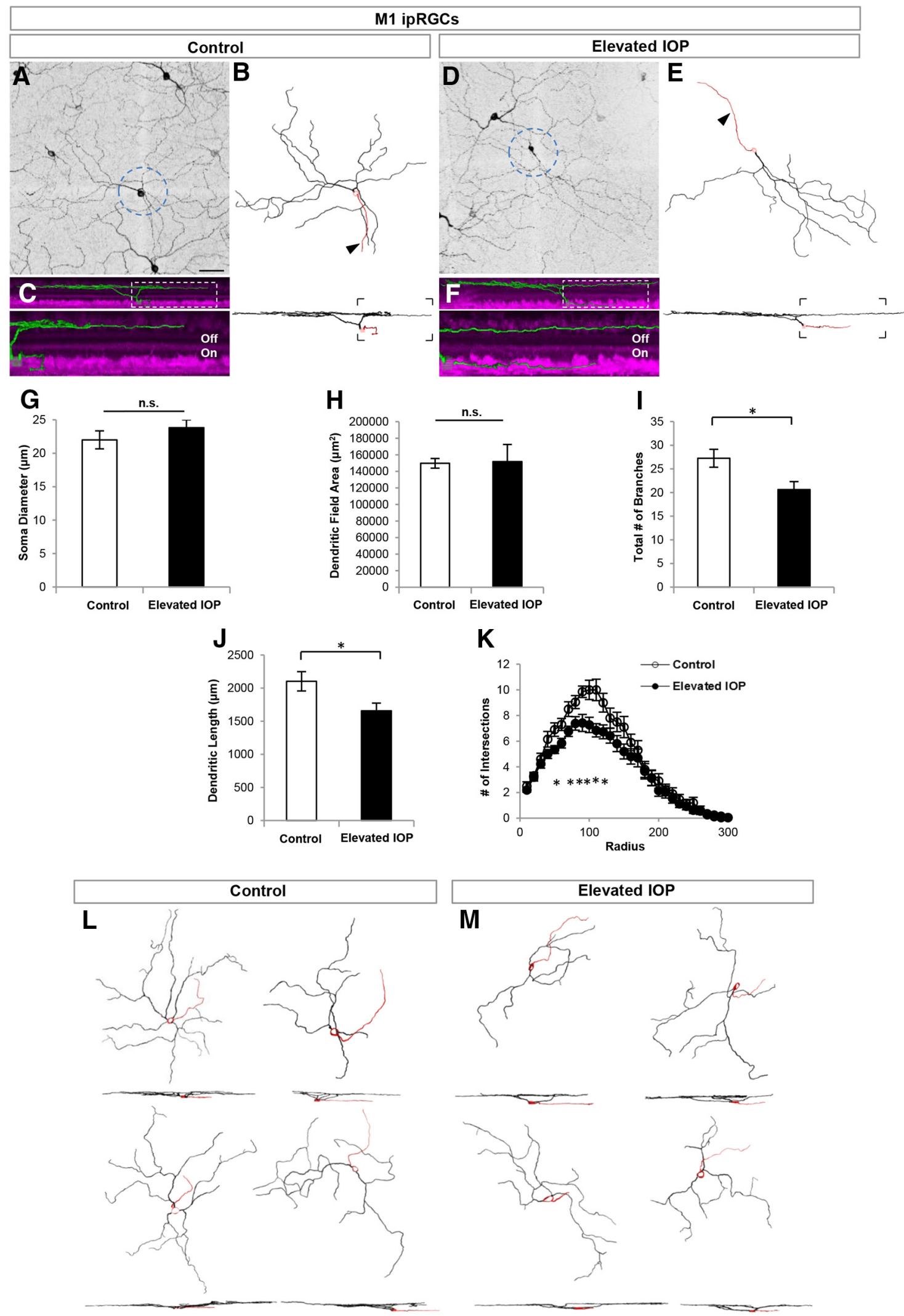

Figure 8. M1 ipRGCs have reduced dendritic branching in response to elevated IOP. A-E, Maximum-intensity projection images showing the morphologies of $M 1$ ipRGCS obtained by immunostaining for melanopsin in control $(\boldsymbol{A}-\boldsymbol{C})$ and IOP-elevated retinas $(\boldsymbol{D}-\boldsymbol{F})$. Reconstructed $M 1$ cells $(\boldsymbol{B}, \boldsymbol{E}$; arrow, axon). $\mathbf{G}-\boldsymbol{K}$, Quantitative morphological comparison of control (white bars) and IOP-elevated (black bars) RGCs showed no significant differences (n.s.) for soma diameter $(\boldsymbol{G})$ and dendritic field area $(\boldsymbol{H})$. Reduction was significant for total number of branches $(\boldsymbol{I})$ and dendritic length $(\boldsymbol{J}) . \boldsymbol{K}$, Sholl analysis showing reduction of branches along distinct locations of the dendritic arbor denoted by asterisks. For $\mathbf{G}-\boldsymbol{K}$, error bars represent $\pm \mathrm{SEM} ; \boldsymbol{t}$ test ${ }^{*} p<0.05$. $\boldsymbol{L}, \boldsymbol{M}$, Representative examples of M1 ipRGCS are shown from control $(\boldsymbol{L})$ and IOP-elevated $(\boldsymbol{M})$ retinas. Scale bars: $\boldsymbol{A}, \boldsymbol{M}, 50 \mu \mathrm{m}$. 

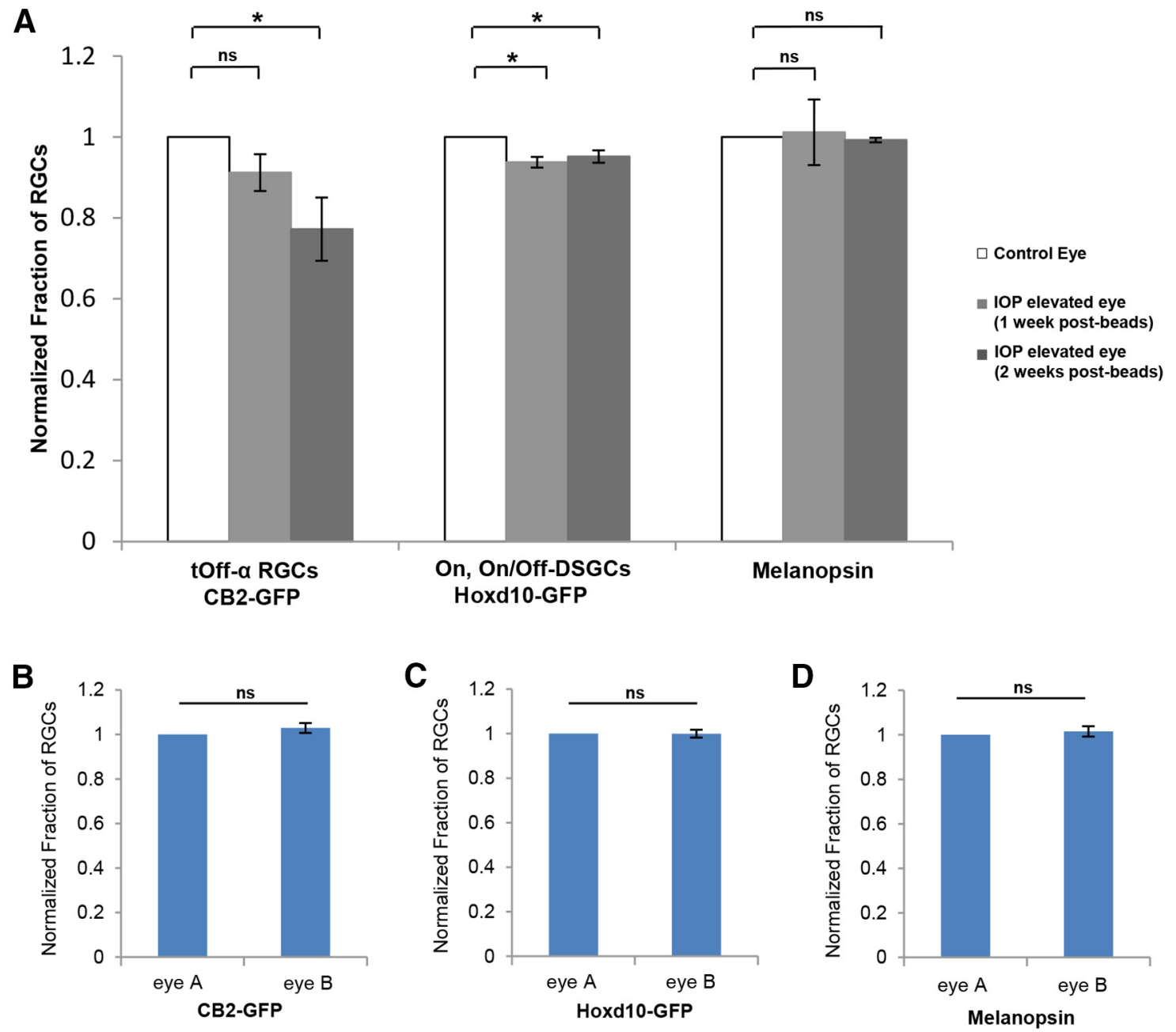

Figure 9. Subtype-specific RGC loss in response to IOP elevation. $A$, Bar graph showing the normalized fraction of RGCs in the different transgenic mouse lines between control (empty bars) and IOP-elevated retinas after 1 (gray bars) or 2 (dark gray bars) weeks after IOP elevation. Total counts of GFP + somata revealed a subtype-specific cell loss in bead-injected retinas, in which the highest degree of cell loss was observed for toff- $\alpha$ RGCs compared with other RGC subtypes. $\boldsymbol{B}-\boldsymbol{D}$, Bar graphs showing the normalized fraction of RGCs between the two eyes of normal, untreated animals in the different transgenic mouse lines, (B2-GFP $(\boldsymbol{B})$ and Hoxd10-GFP ( $\boldsymbol{C}$, as well as for melanopsin-positive RGCs (D). Note that in normal conditions, there are no significant differences (n.s.) in the number of RGCs between the two eyes. For $\boldsymbol{A}-\boldsymbol{D}$, error bars represent \pm SEM. $t$ test ${ }^{*} p<0.01$.

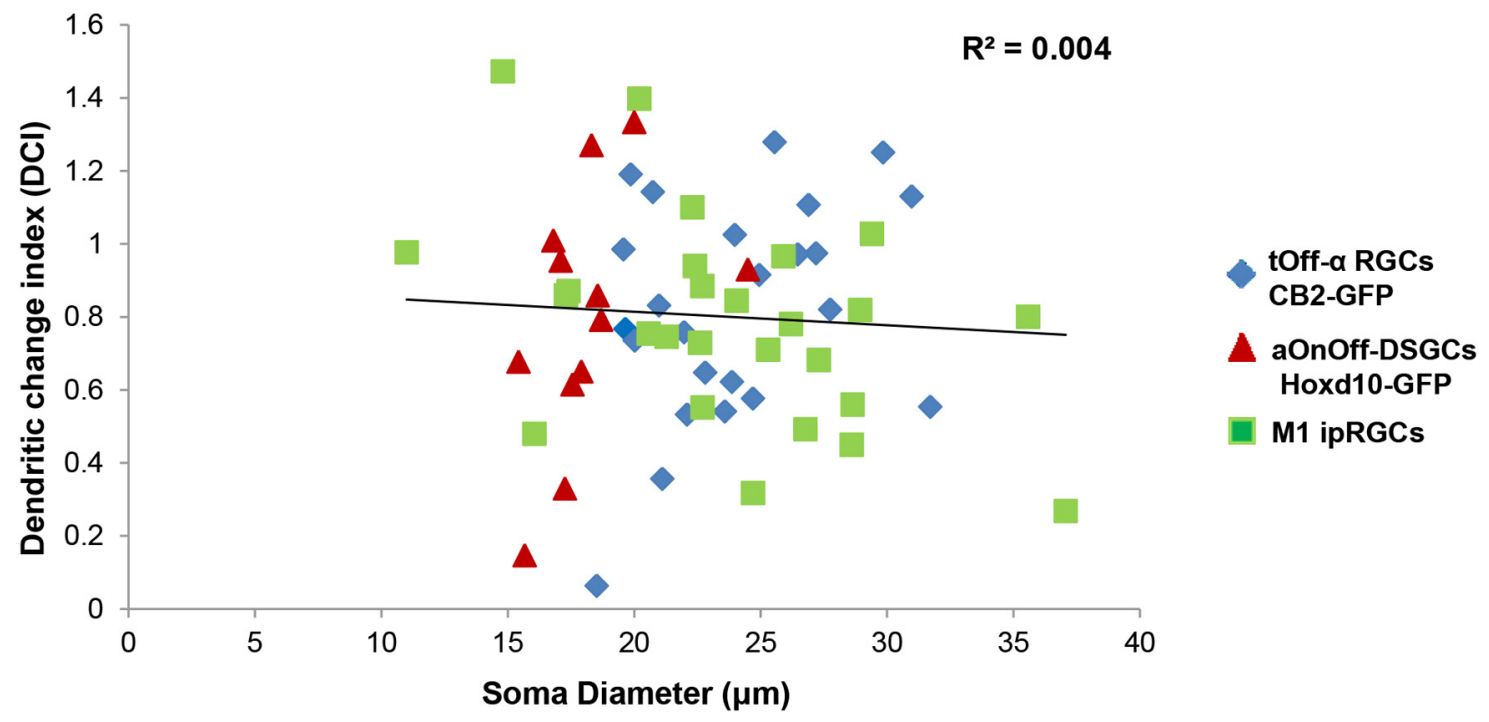

Figure 10. RGC dendritic susceptibility is not correlated to soma size. Scatter plot showing lack of correlation between soma size and the DCI for RGC subtype that showed changes in IOP-elevated retinas. Different colors represent the distinct subtypes of RGCs. Line represents a linear regression fit, with the $r^{2}$ value of 0.004 . 
experimental model found RGC changes, such as defects in axonal transport within the days and weeks immediately following elevations in IOP (Sappington et al., 2010; Chen et al., 2011; Calkins, 2012; Ward et al., 2014), and dendritic changes in RGCs have been reported at $\geq 2$ weeks after IOP elevation, some of which appear to be RGC type specific (Della Santina et al., 2013). In the present study we examined changes in RGC structure within the first week following IOP elevation and by using transgenic mouse lines that selectively express GFP in specific RGC subtypes. The use of transgenic mice enabled us to carefully examine the nature of those dendritic changes in a manner that would be difficult, if not impossible, by random RGC labeling. We discovered that some RGCs show rapid and robust changes in dendritic architecture very soon after IOP increases, and that these changes varied according to dendritic stratification depth in the IPL. Among the four subtypes of RGCs we examined, those that stratify the majority of their dendrites within the On sublamina exhibited no changes, whereas RGCs that stratified most or all their dendrites to the Off sublamina underwent significant rearrangements, such as reductions in overall branching and/or extent.

\section{Identifying the earliest cellular changes in glaucoma}

Wong and coworkers recently showed using the bead model of glaucoma that some RGC subtypes undergo physiological changes before dendritic remodeling (Della Santina et al., 2013). That study focused on changes occurring 15 and $30 \mathrm{~d}$ following induction of elevated IOP by targeting $\alpha$ RGCs on the basis of their soma size. Interestingly, among the RGC types they examined, it was the tOff- $\alpha$ RGCs that displayed the greatest structural and functional changes, including reductions in receptive field size. Their findings are therefore in general agreement with those shown here that tOff- $\alpha$ RGCs undergo marked changes in dendritic field area and symmetry. Based on the early structural changes described here, it would be interesting in future studies to explore whether some RGC subtypes, including tOff- $\alpha$ RGCs, also undergo functional changes within days or even hours of modest IOP elevation. The physiological changes preceding dendritic structural rearrangements reported by Della Santina et al. (2013) were largely attributed to a loss of synapses. Indeed, growing evidence (Ward et al., 2014) points to the idea that synaptic changes may be a critical trigger and/or readout of RGC disruption in early glaucomatous retinas.

The patterns of RGC dendritic changes we observed include reductions in branch number and rearrangements in overall symmetry, both of which may reflect synapse loss. We note, however, that in at least one RGC subtype, the anterior-preferring On-Off bistratified RGCs, the reduction in the overall size of the Off arbors was accompanied by growth of On-stratified arbors in the same cell. Such growth may be compensatory for the loss of Off arbors and may help explain why some studies report reductions in dendritic arbor sizes in glaucoma (Weber et al., 1998; Shou et al., 2003; Jakobs et al., 2005; Della Santina et al., 2013; Feng et al., 2013), while others report increases (Ahmed et al., 2001; Kalesnykas et al., 2012). Overall synapse number in the IPL do not appear altered in glaucomatous retinas until later stages of the disease when many RGCs are lost (Calkins, 2012). However, to our knowledge sublamina-specific changes in RGC synapses have not been examined previously in any glaucoma model. Identifying synaptic changes in the IPL may require the use of tools that label synapses arising from specific types of retinal interneurons onto defined RGC subtypes (Schwartz et al.,
2012) and/or synaptic analysis within the On versus Off retinal sublayers.

\section{Relationship between RGC subtypes and glaucoma}

Our data are to our knowledge the first to explore RGC subtypespecific changes in glaucoma using transgenic markers. While not exhaustive of all 20 RGC subtypes, the mouse lines and molecular markers used here were deliberately selected to encompass a range of RGCs: Off RGCs, On DSGCs, On-Off DSGCs, and a specialized type of On RGC that stratifies in the Off sublamina of the IPL. This, coupled with a now well established glaucoma model, allowed us to test certain longstanding hypotheses in the field about the possible impact of cell size and cell type in early glaucoma-induced degeneration. Previous studies suggested there is cell-type-specific vulnerability in glaucoma, such that larger RGCs are more susceptible (Quigley et al., 1987, 1988; Glovinsky et al., 1991; but see Morgan et al., 2000; Shou et al., 2003; Jakobs et al., 2005). A key limitation of those studies, however, was the lack of tools to reliably distinguish different large RGC subtypes. Therefore, it was unclear whether the preponderance of smaller, denser branching RGCs in glaucomatous eyes reflected, for instance, dramatic shrinkage and remodeling of large ganglion cells, or the survival and increased relative incidence of small cells with normal morphologies. Our data indicate a lack of correlation between soma size and susceptibility to glaucoma, at least for the RGCs examined here using the beadocclusion model in mice at early stages of elevated IOP. Both tOff- $\alpha$ RGCs and On DSGCs have very large dendritic arbors, yet only tOff- $\alpha$ RGCs underwent significant dendritic changes following 1 week of elevated IOP. Furthermore, we found that anterior-preferring On-Off DSGCs, which possess relatively small somas and dendritic arbors compared with $\alpha$ RGCs, exhibited significant morphological changes in response to elevated IOP. We therefore conclude that soma or arbor size alone is not predictive of whether a RGC subtype will undergo morphological changes in response to elevated IOP.

\section{Dendritic stratification: an important correlate of the cell- type vulnerability hypothesis}

A consistent observation made in this study was that RGC subtypes that project the majority of their dendritic arbors to the Off sublayer of the IPL were the ones to undergo the greatest changes in response to elevated IOP. Moreover, such changes were celltype specific: dendrites of tOff- $\alpha$ RGCs, which capture all of their synaptic input from the Off sublamina, underwent dendritic shrinkage and became more asymmetric after IOP elevation. The aOn-Off DSGCs (which stratify $\sim 60 / 40 \%$ in the Off/On sublamina, respectively) showed clear reductions in the extent of their Off arbors and expansion of their On arbors in response to the same manipulation. By contrast, our Sholl analysis of the On DSGCs (which as their name indicates, arborize the majority of their dendrites in the On sublamina of the IPL), underwent no change in overall branching pattern in response to elevated IOP.

Together, these data point to a "selective vulnerability" of RGCs with most of their dendrites projecting into the Off sublamina of the IPL. Stratification depth in the IPL of course relates to RGC subtype and is supported by previous work that examined cell type-specific changes at later stages after elevated IOP (Della Santina et al., 2013). A key difference between our study and previous work is that by comparing On DSGCs, Off RGCs, and On-Off DSGCs, each with different ratios of On/Off arbors in the IPL, we identified the relative percentage of Off versus On arborization as a key predictor of the dendritic changes we ob- 
served in the bead model of glaucoma. Moreover, the M1 ipRGCs, which functionally are On-type cells, but that stratify the majority of their dendrites in the scleral-most portion of the "Off" sublamina, also displayed significant changes shortly after elevated IOP. M1 ipRGC dendrites became sparser and branched significantly less, particularly at locations close to their somas. Together these data suggest that RGCs stratifying in the scleral half of the IPL are especially susceptible in early stages of glaucoma, although there is cell-type specificity in the patterns of dendritic changes that Off-stratifying RGCs undergo in response to IOP elevation.

\section{Off-sublamina vulnerability: possible sources and relevance to clinical/translational studies}

A key question that arises from our findings is as follows: what makes stratification in the Off sublamina (scleral half of the IPL) a predictor of whether RGCs are affected during early stages of elevated IOP? One idea is that the scleral half of the IPL, unlike the vitreal half of the IPL (On sublamina), is highly vascularized with capillaries (Cuthbertson and Mandel, 1986). Previous studies have shown that the vasculature is highly compromised in glaucomatous retinas in both humans and rodent models (Venkataraman et al., 2010; Almasieh et al., 2013). In addition, a recent study in rats showed that there is a significant reduction in the number of capillaries, starting as soon as 3-7 d after elevation of IOP (Almasieh et al., 2013). Given the intimate relationship between vasculature, glial processes, and synapses (Zhang and Stone, 1997; Pournaras et al., 2008), we speculate that vascular damage may be a primary insult leading to the dendritic changes observed here and the synaptic changes reported in previous studies. As such, future explorations of RGC survival in glaucomatous retinas, including both animal models and human retinal imaging studies, may benefit from monitoring stratification depth within the IPL. In the longer term, therapeutic strategies that target endothelial cells, as well as direct neuroprotection, may be of benefit for those suffering from glaucoma, an idea that has already started to gain support from studies of other CNS neurodegenerative diseases, such as Alzheimer's dementia (Halliday et al., 2000; de la Torre, 2004).

\section{References}

Ahmed FA, Chaudhary P, Sharma SC (2001) Effects of increased intraocular pressure on rat retinal ganglion cells. Int J Dev Neurosci 19:209-218. CrossRef Medline

Almasieh M, MacIntyre JN, Pouliot M, Casanova C, Vaucher E, Kelly ME, Di Polo A (2013) Acetylcholinesterase inhibition promotes retinal vasoprotection and increases ocular blood flow in experimental glaucoma. Invest Ophthalmol Vis Sci 54:3171-3183. CrossRef Medline

Beier KT, Borghuis BG, El-Danaf RN, Huberman AD, Demb JB, Cepko CL (2013) Transsynaptic tracing with vesicular stomatitis virus reveals novel retinal circuitry. J Neurosci 33:35-51. CrossRef Medline

Berson DM (2008) Retinal ganglion cell types and their central projection. In: The senses: a comprehensive reference (Masland R, ed). Oxford: Elsevier.

Berson DM, Castrucci AM, Provencio I (2010) Morphology and mosaics of melanopsin-expressing retinal ganglion cell types in mice. J Comp Neurol 518:2405-2422. CrossRef Medline

Bleckert A, Schwartz GW, Turner MH, Rieke F, Wong RO (2014) Visual space is represented by nonmatching topographies of distinct mouse retinal ganglion cell types. Curr Biol 24:310-315. CrossRef Medline

Bouhenni RA, Dunmire J, Sewell A, Edward DP (2012) Animal models of glaucoma. J Biomed Biotechnol 2012:692609. CrossRef Medline

Buckingham BP, Inman DM, Lambert W, Oglesby E, Calkins DJ, Steele MR, Vetter ML, Marsh-Armstrong N, Horner PJ (2008) Progressive ganglion cell degeneration precedes neuronal loss in a mouse model of glaucoma. J Neurosci 28:2735-2744. CrossRef Medline
Calkins DJ (2012) Critical pathogenic events underlying progression of neurodegeneration in glaucoma. Prog Retin Eye Res 31:702-719. CrossRef Medline

Casson RJ, Chidlow G, Wood JP, Crowston JG, Goldberg I (2012) Definition of glaucoma: clinical and experimental concepts. Clin Experiment Ophthalmol 40:341-349. CrossRef Medline

Chen H, Wei X, Cho KS, Chen G, Sappington R, Calkins DJ, Chen DF (2011) Optic neuropathy due to microbead-induced elevated intraocular pressure in the mouse. Invest Ophthalmol Vis Sci 52:36-44. CrossRef Medline

Cone FE, Gelman SE, Son JL, Pease ME, Quigley HA (2010) Differential susceptibility to experimental glaucoma among 3 mouse strains using bead and viscoelastic injection. Exp Eye Res 91:415-424. CrossRef Medline

Crish SD, Sappington RM, Inman DM, Horner PJ, Calkins DJ (2010) Distal axonopathy with structural persistence in glaucomatous neurodegeneration. Proc Natl Acad Sci U S A 107:5196-5201. CrossRef Medline

Cruz-Martín A, El-Danaf RN, Osakada F, Sriram B, Dhande OS, Nguyen PL, Callaway EM, Ghosh A, Huberman AD (2014) A dedicated circuit links direction-selective retinal ganglion cells to the primary visual cortex. $\mathrm{Na}-$ ture 507:358-361. CrossRef Medline

Cuthbertson RA, Mandel TE (1986) Anatomy of the mouse retina. Endothelial cell-pericyte and capillary distribution. Invest Ophthalmol Vis Sci 27:1659-1664. Medline

de la Torre JC (2004) Is Alzheimer's disease a neurodegenerative or a vascular disorder? Data, dogma and dialectics. Lancet Neurol 3:184-190. CrossRef Medline

Della Santina L, Inman DM, Lupien CB, Horner PJ, Wong RO (2013) Differential progression of structural and functional alterations in distinct retinal ganglion cell types in a mouse model of glaucoma. J Neurosci 33:17444-17457. CrossRef Medline

Dhande OS, Huberman AD (2014) Retinal ganglion cell maps in the brain: implications for visual processing. Curr Opin Neurobiol 24:133-142. CrossRef Medline

Dhande OS, Estevez ME, Quattrochi LE, El-Danaf RN, Nguyen PL, Berson DM, Huberman AD (2013) Genetic dissection of retinal inputs to brainstem nuclei controlling image stabilization. J Neurosci 33:17797-17813. CrossRef Medline

Dumitrescu ON, Pucci FG, Wong KY, Berson DM (2009) Ectopic retinal ON bipolar cell synapses in the OFF inner plexiform layer: contacts with dopaminergic amacrine cells and melanopsin ganglion cells. J Comp Neurol 517:226-244. CrossRef Medline

Feng L, Zhao Y, Yoshida M, Chen H, Yang JF, Kim TS, Cang J, Troy JB, Liu X (2013) Sustained ocular hypertension induces dendritic degeneration of mouse retinal ganglion cells that depends on cell type and location. Invest Ophthalmol Vis Sci 54:1106-1117. CrossRef Medline

Frankfort BJ, Khan AK, Tse DY, Chung I, Pang JJ, Yang Z, Gross RL, Wu SM (2013) Elevated intraocular pressure causes inner retinal dysfunction before cell loss in a mouse model of experimental glaucoma. Invest Ophthalmol Vis Sci 54:762-770. CrossRef Medline

Glovinsky Y, Quigley HA, Dunkelberger GR (1991) Retinal ganglion cell loss is size dependent in experimental glaucoma. Invest Ophthalmol Vis Sci 32:484-491. Medline

Halliday G, Robinson SR, Shepherd C, Kril J (2000) Alzheimer's disease and inflammation: a review of cellular and therapeutic mechanisms. Clin Exp Pharmacol Physiol 27:1-8. Medline

Heijl A, Leske MC, Bengtsson B, Hyman L, Bengtsson B, Hussein M, Hussein M (2002) Reduction of intraocular pressure and glaucoma progression: results from the Early Manifest Glaucoma Trial. Arch Ophthalmol 120: 1268-1279. CrossRef Medline

Huberman AD, Manu M, Koch SM, Susman MW, Lutz AB, Ullian EM, Baccus SA, Barres BA (2008) Architecture and activity-mediated refinement of axonal projections from a mosaic of genetically identified retinal ganglion cells. Neuron 59:425-438. CrossRef Medline

Huberman AD, Wei W, Elstrott J, Stafford BK, Feller MB, Barres BA (2009) Genetic identification of an On-Off direction-selective retinal ganglion cell subtype reveals a layer-specific subcortical map of posterior motion. Neuron 62:327-334. CrossRef Medline

Jakobs TC, Libby RT, Ben Y, John SW, Masland RH (2005) Retinal ganglion cell degeneration is topological but not cell type-specific in DBA/2J mice. J Cell Biol 171:313-325. CrossRef Medline

Kalesnykas G, Oglesby EN, Zack DJ, Cone FE, Steinhart MR, Tian J, Pease 
ME, Quigley HA (2012) Retinal ganglion cell morphology after optic nerve crush and experimental glaucoma. Invest Ophthalmol Vis Sci 53: 3847-3857. CrossRef Medline

Kass MA, Heuer DK, Higginbotham EJ, Johnson CA, Keltner JL, Miller JP, Parrish RK 2nd, Wilson MR, Gordon MO (2002) The Ocular Hypertension Treatment Study: a randomized trial determines that topical ocular hypotensive medication delays or prevents the onset of primary openangle glaucoma. Arch Ophthalmol 120:701-713; discussion 829-830. CrossRef Medline

Kim M, Kim DM, Park KH, Kim TW, Jeoung JW, Kim SH (2013) Intraocular pressure reduction with topical medications and progression of normal-tension glaucoma: a 12-year mean follow-up study. Acta Ophthalmol 91:e270-5. CrossRef Medline

Krahe TE, El-Danaf RE, Dilger EK, Henderson SC, Guido W (2011) Morphologically distinct classes of relay cells exhibit regional preferences in the dorsal lateral geniculate nucleus of the mouse. J Neurosci 31:1743717448. CrossRef Medline

Li RS, Chen BY, Tay DK, Chan HH, Pu ML, So KF (2006) Melanopsinexpressing retinal ganglion cells are more injury-resistant in a chronic ocular hypertension model. Invest Ophthalmol Vis Sci 47:2951-2958. CrossRef Medline

Lichter PR (2002) Impact of intraocular pressure reduction on glaucoma progression. JAMA 288:2607-2608. CrossRef Medline

Morgan JE, Uchida H, Caprioli J (2000) Retinal ganglion cell death in experimental glaucoma. Br J Ophthalmol 84:303-310. CrossRef Medline

Morrison JC, Nylander KB, Lauer AK, Cepurna WO, Johnson E (1998) Glaucoma drops control intraocular pressure and protect optic nerves in a rat model of glaucoma. Invest Ophthalmol Vis Sci 39:526-531. Medline

Osterhout JA, Josten N, Yamada J, Pan F, Wu SW, Nguyen PL, Panagiotakos G, Inoue YU, Egusa SF, Volgyi B, Inoue T, Bloomfield SA, Barres BA, Berson DM, Feldheim DA, Huberman AD (2011) Cadherin-6 mediates axon-target matching in a non-image-forming visual circuit. Neuron 71: 632-639. CrossRef Medline

Pang JJ, Gao F, Wu SM (2003) Light-evoked excitatory and inhibitory synaptic inputs to ON and OFF alpha ganglion cells in the mouse retina. J Neurosci 23:6063-6073. Medline

Pascolini D, Mariotti SP (2012) Global estimates of visual impairment: 2010. Br J Ophthalmol 96:614-618. CrossRef Medline

Pavlidis M, Stupp T, Naskar R, Cengiz C, Thanos S (2003) Retinal ganglion cells resistant to advanced glaucoma: a postmortem study of human retinas with the carbocyanine dye DiI. Invest Ophthalmol Vis Sci 44:51965205. CrossRef Medline

Peters D, Bengtsson B, Heijl A (2014) Factors associated with lifetime risk of open-angle glaucoma blindness. Acta Ophthalmol 92:421-425. CrossRef Medline

Pournaras CJ, Rungger-Brändle E, Riva CE, Hardarson SH, Stefansson E (2008) Regulation of retinal blood flow in health and disease. Prog Retin Eye Res 27:284-330. CrossRef Medline

Quigley HA (1999) Neuronal death in glaucoma. Prog Retin Eye Res 18:39-57. CrossRef Medline
Quigley HA, Broman AT (2006) The number of people with glaucoma in 2010 and 2020. Br J Ophthalmol 90:262-267. CrossRef Medline

Quigley HA, Sanchez RM, Dunkelberger GR, L'Hernault NL, Baginski TA (1987) Chronic glaucoma selectively damages large optic nerve fibers. Invest Ophthalmol Vis Sci 28:913-920. Medline

Quigley HA, Dunkelberger GR, Green WR (1988) Chronic human glaucoma causing selectively greater loss of large optic nerve fibers. Ophthalmology 95:357-363. CrossRef Medline

Rivlin-Etzion M, Zhou K, Wei W, Elstrott J, Nguyen PL, Barres BA, Huberman AD, Feller MB (2011) Transgenic mice reveal unexpected diversity of On-Off direction-selective retinal ganglion cell subtypes and brain structures involved in motion processing. J Neurosci 31:8760-8769. CrossRef Medline

Samuel MA, Zhang Y, Meister M, Sanes JR (2011) Age-related alterations in neurons of the mouse retina. J Neurosci 31:16033-16044. CrossRef Medline

Sappington RM, Carlson BJ, Crish SD, Calkins DJ (2010) The microbead occlusion model: a paradigm for induced ocular hypertension in rats and mice. Invest Ophthalmol Vis Sci 51:207-216. CrossRef Medline

Schwartz GW, Okawa H, Dunn FA, Morgan JL, Kerschensteiner D, Wong RO, Rieke F 2012 The spatial structure of a nonlinear receptive field. Nat Neurosci 15:1572-1580. CrossRef Medline

Shou T, Liu J, Wang W, Zhou Y, Zhao K (2003) Differential dendritic shrinkage of alpha and beta retinal ganglion cells in cats with chronic glaucoma. Invest Ophthalmol Vis Sci 44:3005-3010. CrossRef Medline

Sommer A (1989) Intraocular pressure and glaucoma. Am J Ophthalmol 107:186-188. CrossRef Medline

Venkataraman ST, Flanagan JG, Hudson C (2010) Vascular reactivity of optic nerve head and retinal blood vessels in glaucoma-a review. Microcirculation 17:568-581. CrossRef Medline

Vidal-Sanz M, Salinas-Navarro M, Nadal-Nicolás FM, Alarcón-Martínez L, Valiente-Soriano FJ, de Imperial JM, Avilés-Trigueros M, AgudoBarriuso M, Villegas-Pérez MP (2012) Understanding glaucomatous damage: anatomical and functional data from ocular hypertensive rodent retinas. Prog Retin Eye Res 31:1-27. CrossRef Medline

Ward NJ, Ho KW, Lambert WS, Weitlauf C, Calkins DJ (2014) Absence of transient receptor potential vanilloid-1 accelerates stress-induced axonopathy in the optic projection. J Neurosci 34:3161-3170. CrossRef Medline

Weber AJ, Kaufman PL, Hubbard WC (1998) Morphology of single ganglion cells in the glaucomatous primate retina. Invest Ophthalmol Vis Sci 39:2304-2320. Medline

Weinreb RN, Khaw PT (2004) Primary open-angle glaucoma. Lancet 363: 1711-1720. CrossRef Medline

Zhang Y, Stone J (1997) Role of astrocytes in the control of developing retinal vessels. Invest Ophthalmol Vis Sci 38:1653-1666. Medline

Zhao X, Stafford BK, Godin AL, King WM, Wong KY (2014) Photoresponse diversity among the five types of intrinsically photosensitive retinal ganglion cells. J Physiol 592:1619-1636. CrossRef Medline 